\title{
Soil-Water Characteristic Curve of Residual Soil from a Flysch Rock Mass
}

\author{
Josip Peranić, ${ }^{1}$ Željko Arbanas $\mathbb{D}^{1},{ }^{1}$ Sabatino Cuomo, ${ }^{2}$ and Matej Maček ${ }^{3}$ \\ ${ }^{1}$ Faculty of Civil Engineering, University of Rijeka, Rijeka, Croatia \\ ${ }^{2}$ Department of Civil Engineering, University of Salerno, Fisciano, Italy \\ ${ }^{3}$ Faculty of Civil and Geodetic Engineering, University of Ljubljana, Ljubljana, Slovenia
}

Correspondence should be addressed to Željko Arbanas; zeljko.arbanas@gradri.uniri.hr

Received 4 April 2018; Accepted 31 May 2018; Published 29 July 2018

Academic Editor: Ching Hung

Copyright (c) 2018 Josip Peranić et al. This is an open access article distributed under the Creative Commons Attribution License, which permits unrestricted use, distribution, and reproduction in any medium, provided the original work is properly cited.

Depending on the nature of the material and suction range, laboratory measurements of the soil-water characteristic curve (SWCC) can be time-consuming and expensive, especially for residual soils, in which a wide range of particle sizes and soil structures typically results in SWCCs that cover a wide range of suction. Investigations of the SWCCs of residual soil from flysch rock masses are rare, and so far, no results were presented in the literature which were obtained by performing measurements on undisturbed specimens. In this paper, a detailed examination of water retention characteristics is performed for a specific type of residual soil (CL) formed by the weathering of a flysch rock mass. Measurements performed by using different techniques and devices on intact specimens were successfully combined to obtain the SWCC during both drying and wetting processes, under different stress conditions, and from saturated to air-dried conditions. Used procedures are suitable for the determination of SWCCs of soils that undergo volume changes during the drying or the wetting process, since instantaneous volumetric water content can be determined. Results presented in this paper can be used to assess the influence of desaturation of the residual soil covering flysch slopes during dry summer periods by providing key-in material properties required to analyze the transient rainfall infiltration process.

\section{Introduction}

Landslides in flysch deposits frequently occur in European countries such as Italy, Slovenia, Austria, Czech Republic, and Poland and are mainly caused by heavy precipitation. Previous studies of landslides in flysch slopes have mainly focused on the increase in pore water pressure caused by long-term, heavy precipitation as a landslide triggering factor [1] and on the effects of the weathering process of flysch rock masses on the soil shear strength $[2,3]$. The influence of the rainfall pattern and antecedent rainfall, coupled with the unsaturated soil property functions (USPFs) that govern the complex infiltration processes between the soil surface and the phreatic line, was not considered. The aim of this study is to assess the influence of the material behavior above the phreatic line on the infiltration process, since the pore water pressures existing in this zone are generally negative. The complex nature of this material and long periods of heavy rainfall that precede instability phenomena on these slopes suggest that the negative pore water pressure should have an important role in slope stability.

Determination of the SWCCs of residual soils from flysch rock masses is the first step in the analysis of the unsaturated soil behavior in slopes composed of this material. Accuracy of SWCCs largely depends on used techniques and procedures used for the determination of the water retention characteristics. Various techniques use the SWCCs as input data to derive other unsaturated soil property functions, instead of collecting direct measurements. Thus, the precise measurement of SWCCs has an important role in the practical implementation of unsaturated soil mechanics in geotechnical practice. A large part of the existing SWCC database is obtained by performing measurements on specimens prepared using different remolding techniques. Considering the time needed for measuring the SWCCs, the drying process is usually preferred, while the SWCCs obtained during 
the wetting process are rare. Although using reconstituted specimens has clear advantages in terms of the consistency of the test results and homogeneity of the specimens, the measured values are not representative of the material and phenomena occurring in situ. Another important feature of the soil is its hysteretic behavior during the drying and wetting processes, causing significant differences in the matric suction or hydraulic conductivity values obtained for the same soil water content.

The main goal of this paper is to present relevant soilwater retention characteristics and other material properties that are fundamental for modeling the rainfall infiltration process. Since direct measurements are time-consuming, expensive, and difficult procedures, USPFs could instead be estimated based on the data presented in this paper. The procedures used for the determination of the SWCCs in all three characteristic zones: the boundary effect, transition and residual zones [4], and the obtained results, are presented. The most frequently used equations were employed to fit the measurements of the drying and wetting path tests. The obtained parameters can be implemented in future analyses; therefore, the results are discussed and compared to those available in the literature by using comparable materials.

\section{Material and Study Area}

The Rječina River Valley, located in the outback of the city of Rijeka, Croatia (Figure 1), is well known to have experienced numerous historical and recent landslides on both slopes of the valley [1]. The valley is composed of Cretaceous and Paleogene limestone at the top of the slopes and Paleogene siliciclastic rocks and flysch at the lower slopes and the valley bottom, where the sliding processes have primarily developed.

The term flysch was introduced in 1827 by the Swiss geologist Bernhard Studer and originates from the German word fliessen, which means flow. Actually, flysch is a sequence of alternations of various clastic sedimentary rocks that were deposited as a deep marine facies during an early stage of orogenesis. Well-known flysch deposits are found in the forelands of the Pyrenees, Dinarides, northern Alps, and Carpathians and tectonically similar regions in Italy, the Balkans, and Cyprus. Flysch is characterized by rhythmic alternations of sandstone and fine-grained layers that contain siltstones, silty shales, and clayey shales. Flysch deposits may also include breccias, conglomerates, and limestone beds. From a geotechnical point of view, a flysch rock mass could be described by the following characteristics [5]: (i) heterogeneity due to alterations of competent and incompetent members; (ii) the presence of clay minerals; (iii) tectonic fatigue and sheared discontinuities, often resulting in a soil-like material; and (iv) generally low permeability and significant weakening where free drainage does not occur due to the presence of clay minerals.

A flysch rock mass, especially its incompetent members (siltstones and shales), that has been exposed to water and air is strongly affected by chemical weathering and decomposition. These processes cause changes in the physical and mechanical properties. Mechanical weathering also influences the chemical weathering of flysch components. Fine-grained fractions, such as siltstones, are the most affected by chemical weathering [2]. As a result of these processes, the flysch rock mass increases in volume over time, disintegrating to silt or clay. Through this gradual degradation, the physical and mechanical properties of the clayey siltstone materials become similar to engineering soil. A consequence of these types of geomorphological processes is a sporadic accumulation of eroded colluvial deposits on the slopes; these deposits can be susceptible to sliding [6].

Landslides in the flysch slopes occur in two typical forms: (i) deep-seated landslides through the flysch rock mass (some parts of the slip surface could cut through the superficial colluvial deposits) and (ii) shallow landslides with slip surfaces at the contact of the superficial deposits and flysch rock mass or through the superficial colluvial deposits. The type of landslides $[7,8]$ depends on the conditions present in the sliding slope. The main triggering factors are long periods of precipitation, snowmelt, and, rarely, earthquakes.

It was determined that most of the landslides in the Rječina River Valley occurred after long, mostly continuous periods of rain, while short periods of intense precipitation events never initiate a landslide on flysch slopes [9].

A similar scenario was identified in the flysch deposits in Europe, indicating that the main types of instability phenomena in flysch slopes were debris flows and shallow landslides $(<3 \mathrm{~m})$ in superficial deposits and deep-seated landslides with rupture surfaces that cut through the flysch bedrock [6]. The main triggering factors were rainfall and snow melt, while earthquakes also triggered instability phenomena in Italy [10]. The period of cumulative precipitation that caused landslide initiation on the flysch slopes varies in different countries: approximately 90 days in the Istria Peninsula in Croatia [6]; 25-45 days in the Polish Flysch Carpathians [11]; 15-60 days in the Northern Apennines in Italy [10]; 30-60 days in the Southern Apennines in Italy [12]; 25 days in the Slano Blato Landslide area in Slovenia, [13]; and "several months" in the Outer Western Carpathians in the Czech Republic [14]. A longer period, ranging between 180 and 360 days, of accumulated precipitation was associated with major landslide reactivations in the Southern Apennines, Italy [12]. The variability in these findings is due to the different regional and local conditions, but the most important condition associated with the time to landslide activation is the rate of surface water infiltration.

The infiltration process has a main role in landslide initiation, influencing the soil saturation, the behavior and strength of the soil in the unsaturated zone above the groundwater level, the changes in the soil unit weight, the groundwater level rise, and the overall relation between the active forces and soil resistance in a slope. Knowledge and understanding of soil-water characteristics are necessary conditions for the explanation of the landslide initiation on flysch slopes. Investigations of the soil-water retention characteristic of residual soil from flysch rock masses are very rare, and only a few valuable results have been presented in the literature.

The Valići Landslide occurred on 13 February 2014 at the southwestern slope of the Rječina River Valley after a long period of heavy rain $[9,15]$. Undisturbed soil samples were 

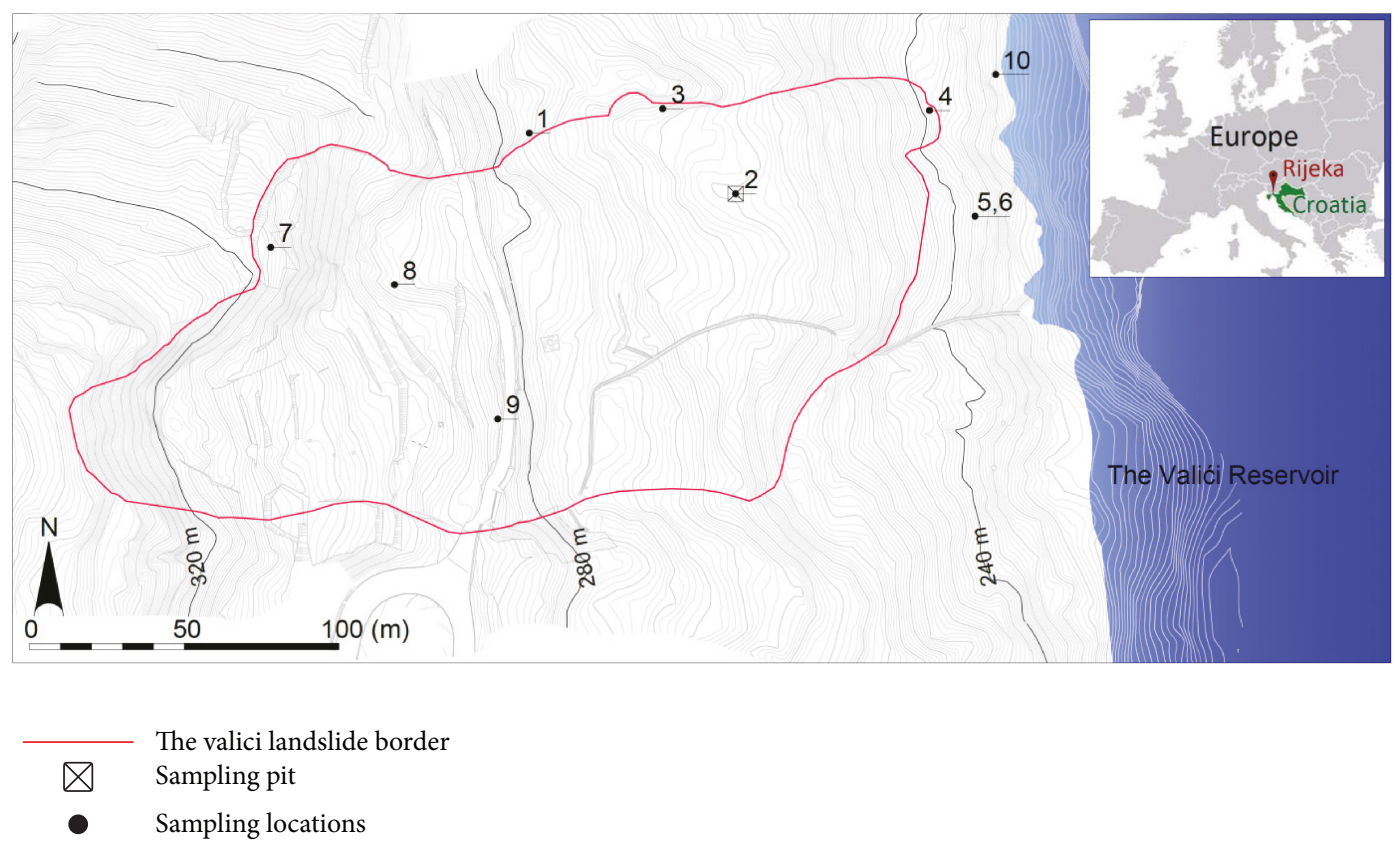

FIgURE 1: Map of the reactivated landslide on a detailed topographic map with sampling positions [9].

collected from the sample pit in the central part of the Valići Landslide (position 2 in Figure 1), and a series of tests were conducted to determine the basic index properties of the soil. Sampling was performed from the surface at a small handdrilled pit by using hard-plastic tubes (Figure 2(a)). The sampling depths for all the samples varied from 0.5 to $1 \mathrm{~m}$. After pushing the tubes into the soil, they were excavated and sealed to prevent evaporation. The natural water content ranged from $28 \%$ at the ground surface to $10 \%$ at a depth of $1 \mathrm{~m}$, while the in situ density varied from 1.91 to $2.13 \mathrm{~g} /$ $\mathrm{cm}^{3}$. The mean values of the basic properties of the tested material, including the specific gravity of soil solids (ASTM D854-14) [16], saturated unit weight, particle size distribution (ASTM D1140-17 [17] and ASTM D7928-17 [18]), liquid limit $\left(w_{\mathrm{L}}\right)$, plastic limit $\left(w_{\mathrm{P}}\right)$, plasticity index $(\mathrm{PI})$ (ASTM D4318-17) [19], and classification of material according to the USCS (ASTM D2487-11) [20], are summarized in Table 1.

\subsection{Grain Size Distribution (GSD) Analysis and Plasticity} Limits. The inverse distribution of the solid particles (e.g., the distribution of the voids), for each material type, provides an insight into the possible unsaturated soil behavior and soil-water retention characteristics.

To analyze the possible GSD characteristics of the material in the landslide body, samples were taken from the landslide surface at 10 different locations, which are marked in Figure 1. Wet sieving tests, the hydrometer method, and particle sizing by using the SediGraph method were combined to obtain the GSD curves. The obtained results (Figure 3) show that fine-grained particles dominate in the tested samples with the highest average contents of silt and clay.

GSD curves show a similar grain-size composition of the material along different parts of the landslide surface, indicating similar conditions in the material origin due to the weathering process of the bedrock siltstone. The only sample that had a slightly higher content of sand particles (28.2\%) was sample number 10 , which was collected outside the landslide body at the lowest position of the slope. The largest quantity of particles larger than $2 \mathrm{~mm}$ was found in samples collected from the central part of the landslide body (points 2, 8 and 9), and the sample from location number 9 had the highest content (9.5\%) by weight.

The Atterberg limits were determined, and most of the materials could be classified as low-plasticity clay (CL). Only samples taken from locations number 8 and number 10 are plotted beneath the A-line in the plasticity chart. The obtained results cluster in the plasticity chart, indicating that the whole landslide body has uniform material properties (Figure 4).

Unlike in the case of disturbed and compacted specimens, in successive tests for different purposes, undisturbed specimens could be characterized as highly heterogeneous on the macroscale. Heterogeneity arises from the presence of macroscale voids caused by the biological activity of worms and roots in the soil close to the surface or arises from the presence of silt grains that can vary in size and weathering degrees (Figure 2(b)). Such heterogeneous results create difficulties when performing laboratory tests on small specimens. However, in the sense of the granulometric composition and plasticity limits, the material located near the ground surface seems to be very homogeneous. It is well known that granulometric composition and plasticity limits are directly connected with water retention capabilities and hydraulic conductivity features of a material. Therefore, the identification test results indicate that the superficial residual soil should have similar USPF characteristics. 


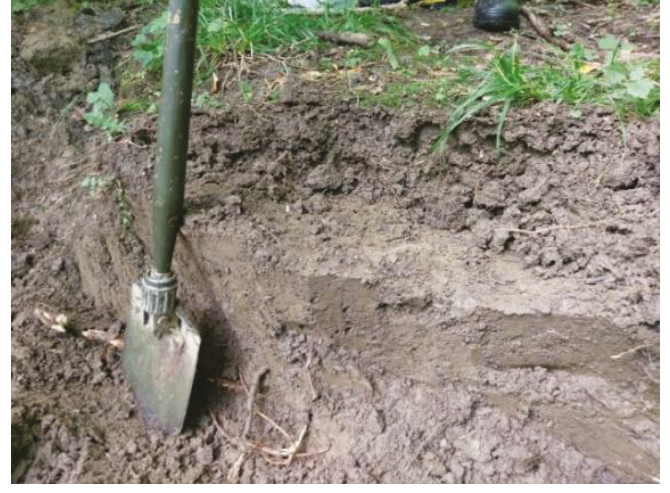

(a)

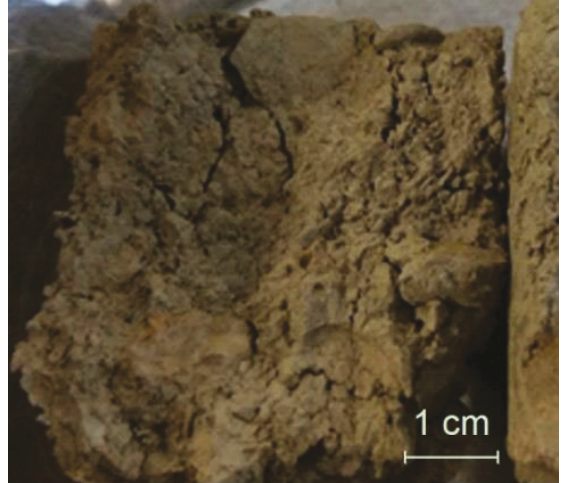

(b)

FIgUre 2: (a) Sampling pit. (b) Half of the oven-dried specimen from a depth of $0.75 \mathrm{~m}$.

TABLE 1: Mean values of the basic properties of the residual soil samples used in this study.

\begin{tabular}{|c|c|c|c|c|c|c|c|c|c|}
\hline \multirow[b]{2}{*}{$\begin{array}{l}\text { Specific gravity, } \\
G_{s}(/)\end{array}$} & \multirow[b]{2}{*}{$\begin{array}{l}\text { Sat. unit weight, } \\
\gamma_{\mathrm{s}}\left(\mathrm{kN} / \mathrm{m}^{3}\right)\end{array}$} & \multicolumn{4}{|c|}{ Particle size distribution } & \multicolumn{2}{|c|}{ Atterberg limits } & \multirow[b]{2}{*}{$\begin{array}{l}\text { Plasticity } \\
\text { index, PI }\end{array}$} & \multirow[b]{2}{*}{ USCS } \\
\hline & & $\begin{array}{l}\text { Clay, } \\
C(\%)\end{array}$ & $\begin{array}{l}\text { Silt, } \\
M(\%)\end{array}$ & $\begin{array}{l}\text { Sand, } \\
S(\%)\end{array}$ & $\begin{array}{c}\text { Gravel, } \\
G(\%)\end{array}$ & $\begin{array}{l}\text { Liquid limit, } \\
w_{\mathrm{L}}(\%)\end{array}$ & $\begin{array}{c}\text { Plastic limit, } \\
w_{\mathrm{P}}(\%)\end{array}$ & & \\
\hline 2.7 & 20.9 & 30.3 & 53 & 10.4 & 6.3 & 44 & 24 & 20 & CL \\
\hline
\end{tabular}

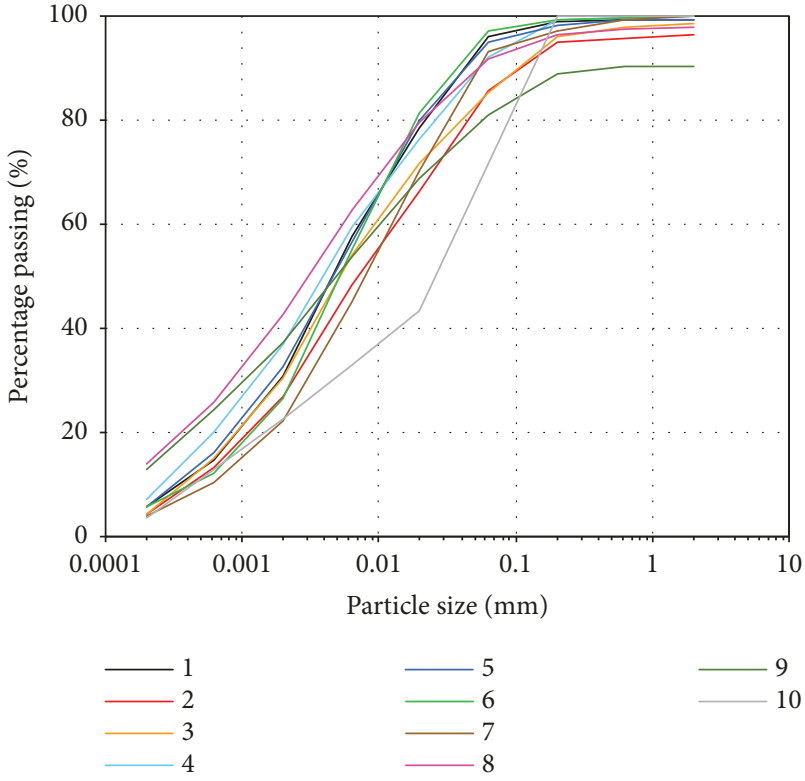

FIGURE 3: GSD results for samples collected at 10 locations along the landslide body and slope.

\section{Methods Used for Determination of Soil-Water Characteristic Curves}

A SWCC is one of the most important features in unsaturated soil mechanics and relates to the potential energy of a liquid phase, which is usually characterized by the suction $\psi$, to the variations in the water content $w$ in the soil [21]. Depending on the material behavior of the soil as the suction varies, the soil water content is commonly designated in terms of the gravimetric water content $w$, volumetric water

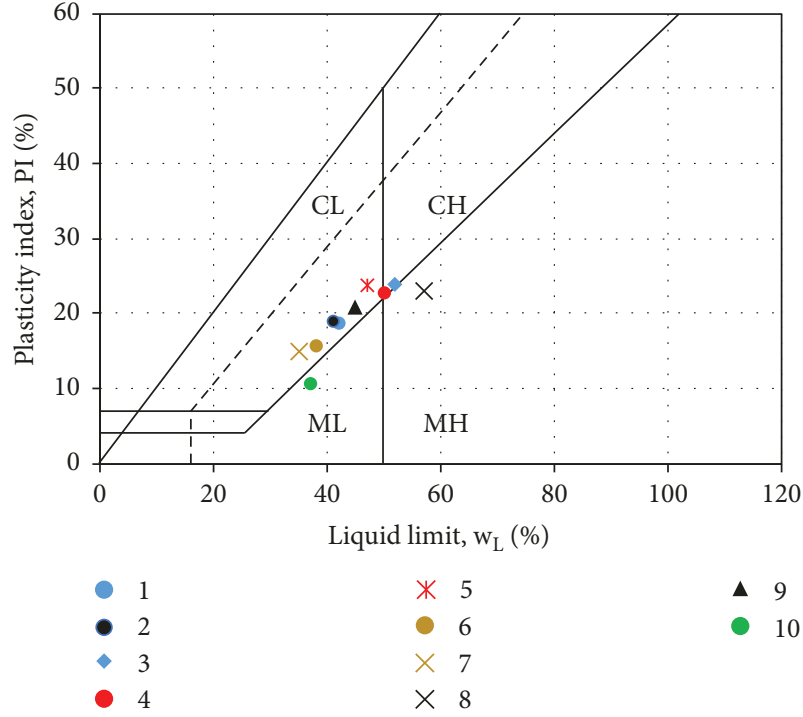

Figure 4: Plasticity chart of the samples.

content $\theta$, or degree of saturation $S$. For compressible soils that undergo a change in volume with a change in the suction, both the changes in water volume change and total volume should be measured [22]. For a single type of material, the SWCC should be presented in terms that consider both phenomena $(\theta, S)$. Different approaches were developed for the accurate determination of the SWCCs of different types of soils. Different measuring techniques and devices were developed to measure the water retention characteristics at different suction ranges. The existing devices and testing procedures were often modified to adjust for different factors that affect the measurement results. 
3.1. Literature Overview. Many studies were conducted to assess the influence of different factors on the water retention properties of the soil in geotechnical engineering applications.

Numerous investigations (e.g., [23-26]) noted that the void ratio, water content, and stress state of a soil have a strong influence on the SWCC. Standard laboratory equipment based on the axis translation technique, such as the pressure plate, volume extractor, suction-controlled oedometer, modified triaxial apparatuses, and standard tensiometers, are the most common devices used to control or measure matric suction. Although every type of the abovementioned equipment has some advantages and limitations, they can be combined to measure or control matric suction up to $1500 \mathrm{kPa}$. Generally, capillary forces dominate the wet range and adsorptive surface forces dominate the dry range of the SWCC. Measurement accuracy in the dry area of the SWCC, such as those above $1 \mathrm{MPa}$ of suction, has greatly benefited from the development of precise chilled hygrometers [27]. Gee et al. [27] noted that the structural changes induced by sampling should have a minimal impact on the measured water potential at low water contents. They concluded that for low water contents, SWCCs are controlled by a surface area rather than pore geometry. A dew-point potentiometer device (Decagon Devices Inc.) was used to investigate water retention characteristics of different soil types (e.g., [28-31]).

Agus and Schanz [32] compared four laboratory methods commonly used for measuring soil total suction by using two bentonite-sand mixtures: the noncontact filter paper method, the psychrometer technique, the relative humidity $(\mathrm{RH})$ sensor, and the chilled-mirror hygrometer technique. They concluded that the chilled-mirror hygrometer technique was the most accurate among the four methods used in the study. Campbell et al. [33] presented a procedure for specimen preparation, suction, and water content measurements during a wetting process using the WP4-T apparatus.

In this paper, different testing devices were used to cover the wide range of suctions that this material can exhibit. All tests were performed to measure both the (matric) suction and the volumetric water contents during the drying and wetting processes in undisturbed specimens.

3.2. Testing Programme. All the undisturbed samples used to determine the SWCC were taken from the same sample pit in the central part of the Valići Landslide (position 2 in Figure 1). By using different devices and measurement techniques in their optimum measuring ranges and combining the measurement results, a SWCC was defined in all three characteristic zones of desaturation. For testing the residual soil from the flysch rock mass at a low range of matric suctions, different testing conditions were used to simulate the field conditions that can affect SWCCs. The effect of the overburden pressure on the SWCC was analyzed using different values of the net vertical stress and suction-controlled oedometer-type devices. The measurements collected during the drying and wetting processes were performed using multiple devices to identify the hysteresis and retention characteristics that material exhibits in situ during rainfall infiltration or evaporation. The influence of different initial water contents and saturation conditions was examined by measuring different scanning curves, starting from initially saturated conditions, natural water content conditions, or air-dried conditions. To identify the possible effects of the soil structure and the sample preparation method on the suction measurements using a WP4-T device, the measurements were performed on undisturbed specimens that were prepared using commonly adopted specimen preparation techniques for testing with the WP4-T device, as proposed by various authors (e.g., $[30,33])$, for both the drying and the wetting paths. Due to shortcomings of the axis translation technique for measurements of soil suction at high degrees of saturation [34], minitensiometer measurements were used to determine the wet part of the SWCC more precisely.

3.3. Standard and Volumetric Pressure Plate Extractor Apparatus. A pressure plate extractor apparatus (Soilmoisture Equipment Corp.) with $1500 \mathrm{kPa}$ ceramic plates was used on undisturbed samples to obtain results of the drying branch of the SWCC, for up to $700 \mathrm{kPa}$ of matric suction. The tests were performed on undisturbed specimens with the diameter of $51 \mathrm{~mm}$ and height of $10 \mathrm{~mm}$. A short specimen height was used to shorten the equilibration time. At higher water contents, caliper measurements of the total volume have shown to be inapplicable due to the soft consistency of the samples. Wax dipping and the water displacement techniques (ASTM D7263-09) [35] were used to determine the total density of a single specimen after every equilibration step. The total volume measurement, combined with the gravimetric measurement for the determination of the water content according to ASTM D6836-02 [36], enabled the use of the conventional pressure plate extractor apparatus to obtain a more advanced characterization of the soil-water retention properties than that possible with a conventional $\psi-w$ relationship. The results obtained using this device and the adopted testing procedure enabled the evaluation of the change in the void ratio and degree of saturation due to the increase in matric suction during the drying process of the undisturbed samples, up to $700 \mathrm{kPa}$. Gravimetric water content measurements were performed on multiple specimens during the RP03 test (samples se1 to se7), starting from the natural water content $w_{\mathrm{n}}$. To minimize evaporation from the samples during the density measurement, volume measurements were performed only on one sample (RP03se1) after every equilibration stage.

A volumetric pressure plate (Soilmoisture Equipment Corp.) extractor with a $200 \mathrm{kPa}$ ceramic plate and hysteresis attachments was used to determine the hysteresis of the soil in the low matric suction range. Test VE-1w was performed on an undisturbed specimen previously equilibrated in a standard pressure plate extractor apparatus at a matric suction of $300 \mathrm{kPa}$. The total volume change measurements were performed after every equalization step, using the previously described procedure. The water content was calculated after every equilibration step using the gravimetric or volumetric measurements of the water volume change.

3.4. Suction-Controlled Oedometer Apparatus. Two different suction-controlled oedometer-type devices were used for a 
more advanced investigation of the soil-water retention properties through the control of the stress state variables (net vertical stress and matric suction) and measurements of the axial deformations of the sample and water volume variations during the test. Automated data acquisition during the test is an important advantage over the previously described null-type axis-translation devices, especially for the long-lasting wetting tests. The main advantage of the suction-controlled oedometer apparatus (SCOED) at UniSa is the advanced air-flushing system, which removes diffused air beneath the high air entry porous disc (HAEPD) and consists of two double-wall burettes coupled to a differential pressure transducer and a peristaltic pump. HAEPDs with 200 and $500 \mathrm{kPa}$ AEV were used to perform different types of tests. The Hydrocon hydraulic consolidation cell for unsaturated samples (Controls S.p.A.), used at UniRi, enables sample saturation through back pressurization in a confined system. The apparatus was equipped with a $1 \mathrm{MPa}$ HAEPD. These devices were used to perform multiple (main and scanning) drying and wetting tests on undisturbed specimens with different net vertical stresses. Tests UVH-1, UVH-2, and UVH-3 were performed using the Hydrocon device to obtain the main drying curves under net vertical stresses of 25,100 , and $200 \mathrm{kPa}$, respectively. Test OEUVCJ01 was performed using the SCOED apparatus and included a scanning drying and wetting test at a net vertical stress of $200 \mathrm{kPa}$, while test OEUVCJ03w was performed on an oven-dried sample during the wetting path, using a net vertical stress of $5 \mathrm{kPa}$ to measure the vertical deformations during the wetting test. Following this test, the sample was consolidated at $200 \mathrm{kPa}$, and test OEUVCJ03 was performed during the drying path.

3.5. HYPROP Evaporation Method Device. The HYPROP evaporation method device (Decagon Devices Inc.) was used to determine the wet part of the SWCC more precisely. Tests were performed on three undisturbed specimens with different initial water contents, starting from the saturated water content or from the natural water content. Saturation of the specimens prior to testing was performed inside a steel cylinder either by immersion in water or by immersion in water with the application of a small vacuum. The water loss from the sample due to evaporation is automatically recorded by placing the sample on a high-precision scale, and the negative water pressures are measured directly using two minitensiometers installed in predrilled holes at different heights. No volume changes were measured due to evaporation during the suction increase; therefore, the obtained results are shown in terms of only the gravimetric water content $w$. However, information on the hydraulic gradient between two measuring points and the water flux can be used to calculate the unsaturated hydraulic conductivity in the measured range, according to the DarcyBuckingham law. Due to cavitation problems when using direct tensiometer measurements, the simplified evaporation method [37] is frequently used for measuring both the SWCC and the suction permeability curve in sands and silts. By using the tensiometer-preconditioning procedure [38], the results were obtained for matric suctions up to $130 \mathrm{kPa}$. The results obtained from the sample starting from the natural water content are denoted by HYPROP-2.

3.6. Dew-Point Potentiometer WP4-T. The WP4-T (Decagon Devices Inc.) potentiometer device was used to measure the suction in the dry area of the SWCC, extending into the midrange. A detailed description of the dew point device that measures the total suction by the vapor pressure method is provided by Leong et al. [29] and Campbell et al. [33]. The device was used to obtain the soil-water characteristics of undisturbed and remolded specimens undergoing drying and wetting processes. Testing procedures were conducted according to ASTM D 6836-02, in combination with density measurements after each suction measurement, by using the wax dipping and water displacement technique (ASTM D7263-09) [35]. The measurements were extended into the midrange of the SWCC for undisturbed and remolded soil specimens to compare the measurement results. In the first test (WP4-T-1), a total of 8 completely remolded specimens were prepared and equilibrated at different water contents, using the specimen preparation procedure similar to that described by Campbell et al. [33]. Test WP4-T-2 was performed during the wetting process on 11 completely remolded samples prepared using the specimen preparation procedure proposed by Campbell et al. [33]. In this test, only the water content was measured during the wetting process. Another test (WP4-T-3) was performed on 9 undisturbed specimens prepared at a natural water content. The first three specimens (WP4-T-3se1, WP4-T-3se2, and WP4-T-3se3) were submerged in water and left to saturate for $24 \mathrm{~h}$. The measurements of the next three specimens were performed starting from the natural water content and were slowly airdried (WP4-T-3se4, WP4-T-3se5, and WP4-T-3se6). The last three specimens (WP4-T-3se7, WP4-T-3se8, and WP4$\mathrm{T}-3 \mathrm{se} 9$ ) were used to perform measurements during the wetting process, starting from the air-dried condition. Air-dried specimens were wetted with a small amount of water and rested for approximately 24 hours in small sealed plastic bags. After each step of the equilibration, the suction and weight of the specimen were measured. Then, the total density of the specimens was measured, and the procedure was repeated until the suction values became too low during the wetting process or until the air-dried conditions were achieved during the drying process. During both the drying and the wetting processes, multiple measurements of the suction and density were performed. Suction values as low as $230 \mathrm{kPa}$ and higher than $90 \mathrm{MPa}$ were measured using the WP4-T device.

\section{Test Results}

The matric suction and total suction measurements were combined to define the soil-water characteristics from the capillary saturation zone to the zone of residual saturation. All the results were obtained from undisturbed specimens, except for the drying test WP4-T-1 and wetting test WP4T-2. Different colors are used to highlight different specimen conditions at the start of the test, in terms of the saturation and preparation technique. Markers with solid fill indicate 
that disturbed specimens were used in the test. Red and blue colors indicate that the drying path started from saturated conditions or natural water content conditions, respectively, while the green color is used to represent the measurements obtained from specimens undergoing wetting.

The results obtained from air-dried samples prior to the wetting path are used for hydraulic characterization of the soil in the wetting process, and results obtained from only undisturbed soil specimens were used for the development of the SWCC. By comparing the results obtained from the disturbed and undisturbed specimens using the same device or technique, the influence of the specimen preparation method and soil structure on the measured values could also be evaluated.

The measurement results used to obtain the suction $\psi$ versus the water content $w$ SWCC (SWCC- $w$ ) are presented in Figure 5(a). Some of the results obtained using the standard and volumetric pressure plate extractor devices, suction-controlled oedometer devices, HYPROP and WP4$\mathrm{T}$ devices are included. The suction $\psi$ versus the volumetric water content $\theta$ (SWCC- $\theta$ ) results are presented in Figure 5(b), for the measurements that show changes in both the water volume and the total volume (or density) due to the suction change during the test. For the suction-controlled oedometer devices, the total volume was calculated using the measured axial deformations, assuming no specimen sidewall detachments.

The slope of the drying branch in the SWCC before reaching the $\mathrm{AEV}$ of the material is visible for both the SWCC $-w$ and the SWCC- $\theta$, indicating that the material undergoes a volume change when the suction is increased, due to the increase in the stress state of the soil. Many studies (e.g., $[39,40])$ have concluded that the rate of the volume change in the saturated part of the SWCC depends on the stress history of a soil. However, the total volume change should not affect the degree of saturation of deformable soil before the AEV of the soil is reached. The degree of saturation remains equal to unity, and the SWCC-S plot should remain horizontal until the AEV of the material is reached. After this point, desaturation starts at a rate that depends on the features of the material being tested. By plotting a large number of experimental data on a log-log plot of the suction $\psi$ versus the effective degree of saturation Se, Brooks and Corey [41] found that the rate of desaturation exhibits a linear shape for the unsaturated part of the SWCC. This approach was used to avoid the usual difficulties in the determination of the true AEV due to the volume changes in the saturated part of SWCC $([39,42])$.

The SWCC results are shown in the SWCC-S form in Figure 6. A semi-log plot is shown in Figure 6(a) for tests in which the degree of saturation could be calculated. For the remolded specimens, the density measurements were combined with the standard WP4-T suction and water content measurements for only the drying test WP4-T-1, and the WP4-T-2 results are not included. In Figure 6(b), the SWCC-S results are presented in a log-log plot. Using the plot and results from the unsaturated linear part of the SWCC, the AEV of $210 \mathrm{kPa}$ and air expulsion value (AExV) of $56 \mathrm{kPa}$ were determined for the drying and wetting paths.
The regression lines for the drying and wetting processes are parallel, and the value of the pore-size distribution index $\lambda$ [41] is 0.26 , which seems to not be affected by the ongoing process type. However, the results obtained from the remolded specimens along the drying path (WP4-T-1) show a deviation from the abovementioned values, with a higher $\operatorname{AEV}(450 \mathrm{kPa})$ and higher desaturation rate $(\lambda=0.33)$.

Hysteresis between the drying and the wetting processes is observed for all the SWCC plots. The shape of the SWCC, saturated water contents, and other soil properties associated with the drying and wetting SWCC paths [43] suggest that the tested material is more similar to silty soil than clayey soil [44]. Another important observation from the wetting tests is that the specimens did not reach full saturation. Similar results are obtained for drying tests performed on samples that were saturated prior to testing by submerging into water. The obtained volumetric water contents typically corresponded to $80-95 \%$ of the saturated water content values. Similar observations were noted by other researchers. Chiu and Shackelford [45] obtained maximum volumetric water contents $\theta_{\mathrm{m}}$ from 0.84 to 0.90 of the saturated value $\theta_{\mathrm{s}}$ during the wetting process of compacted sand-kaolin mixtures. After several days of soaking, Perera et al. [46] determined that the degree of saturation was $87 \%-100 \%$ for the clayey samples.

The influence of the sample preparation technique on the measurement results obtained using the WP4-T device is highlighted in Figure 5(a) (SWCC- $w$ ), for both the drying and the wetting paths. For the drying path, the measured results from the remolded specimens plot higher than the results obtained from the undisturbed specimens, especially for suction values below $1000 \mathrm{kPa}$. The effects of the sample preparation method and the soil structure on the measurements start to wane above a suction of $1000 \mathrm{kPa}$ for the drying branch. The influence of the specimen preparation method is even more emphasized in the case of the results obtained during the wetting process (WP4-T-2). The results start to deviate from those obtained from the undisturbed samples when the suction values become lower than $6000 \mathrm{kPa}$.

In contrast, the measurements obtained from the undisturbed specimens using the WP4-T device seem to be in good agreement with the measurements obtained using the axis translation technique, even for the suction values well below $1000 \mathrm{kPa}$. This could indicate that the soil structure does have an important effect on the results obtained using the WP4-T device in the part of the SWCC with lower suction values and that the measurements from the undisturbed specimens should be preferred when using the WP4-T device and when the suction values of interest are lower than $1 \mathrm{MPa}$.

The results obtained on undisturbed specimens underline the smooth and gradual transition between the saturated and unsaturated parts of the SWCC. This feature of the soil is closely related to the water retention and permeability characteristics and should thus have a direct influence on the rainfall infiltration process occurring in the slopes in situ. For sands and slits, the transition zone of the SWCC is generally steep, indicating higher rates at which the material can be saturated during the infiltration process 


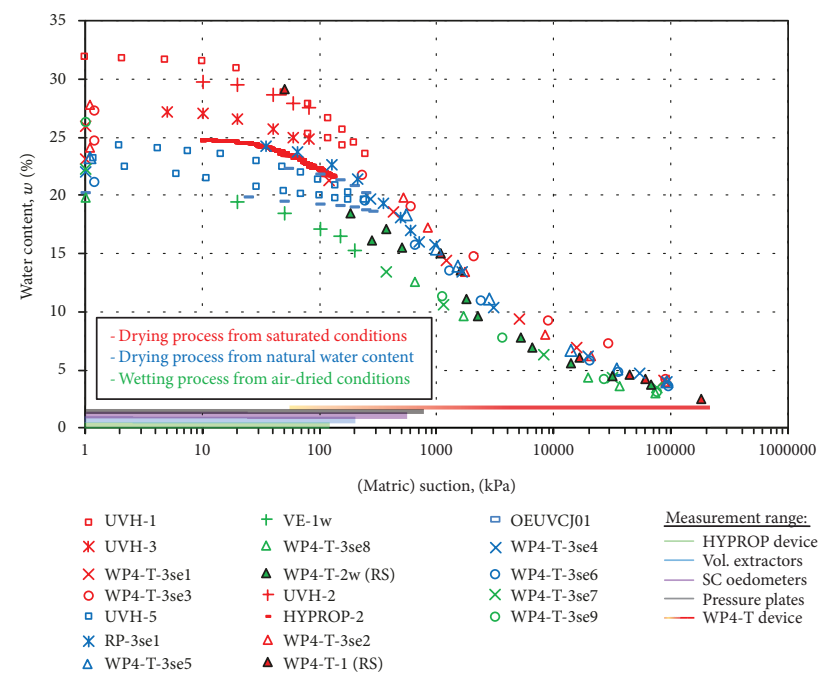

(a)

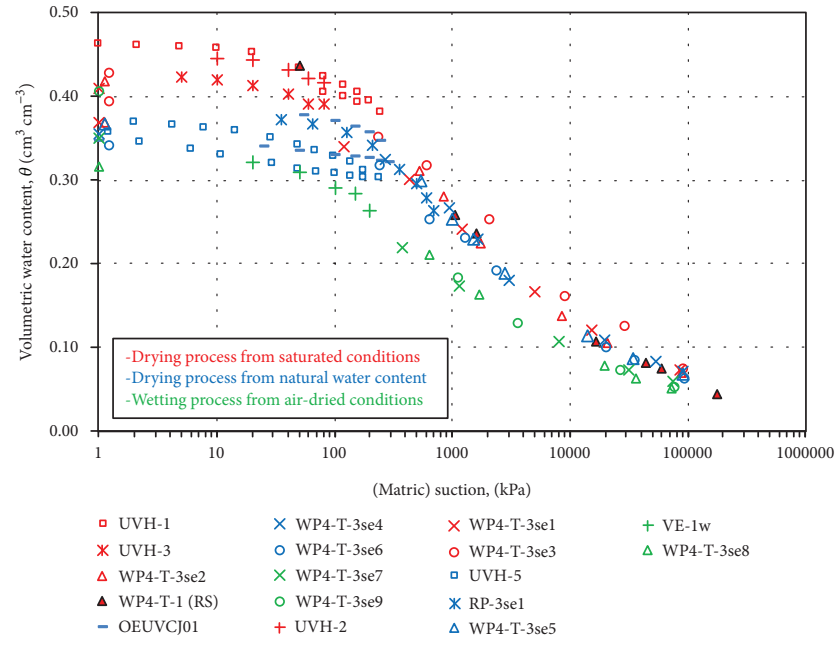

(b)

FIGURE 5: SWCC in terms of (a) gravimetric water content and (b) volumetric water content for the drying and wetting processes. Symbol (RS) indicates remolded samples; all other samples are undisturbed.

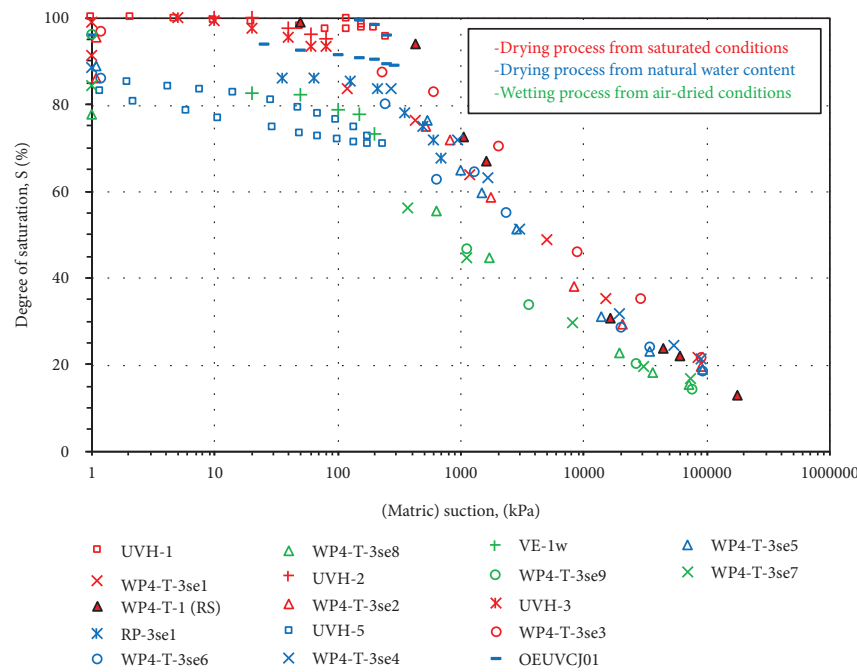

(a)

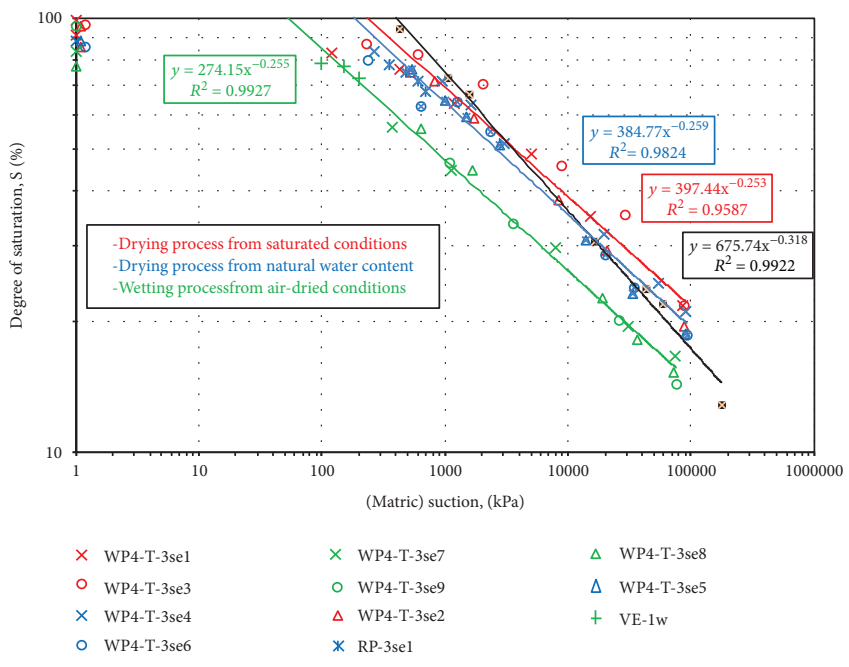

(b)

FIGURE 6: Drying and wetting paths of the SWCC-S at (a) semilog and (b) log-log scale.

or desaturated during evapotranspiration. Consequently, short-duration precipitation with higher intensities is the common triggering factor for landslides occurring in these types of material ([47-49]). In contrast, the SWCCs with gentle slopes in the transition zone imply low rates of change in the water content in the soil. Long evaporation periods are required to significantly dry these types of soils, and long infiltration periods are required for water to saturate these types of soils.

The density measurements combined with the standard $\psi-w$ measurements from the pressure plate and WP4-T devices, and the measurements by the suction-controlled oedometer devices can provide an insight into the volume changes affected by the change in suction. Figure 7 presents the $e-S-\psi$ relationship for the specimens that underwent zero total stress and total density measurements after every measurement of the (total) suction or equalization step. The results obtained using the standard pressure plate apparatus and WP4-T device are included here.

The results obtained using the standard and suctioncontrolled oedometer apparatuses are shown in terms of the effective stress $\sigma^{\prime}$ versus the void ratio $e$ in Figure 8(a). The effective stress is defined using the Bishop's effective stress formulation [50] and the Khalili and Khabbaz [51] expression for the effective stress parameter. Since the suction stress is not in the main focus of this paper, more recent papers on this topic can be found elsewhere (e.g., see [52-55] and [56]). The results show that the effective stress approach works well for the results obtained on the undisturbed specimens in the range of the effective stress considered 


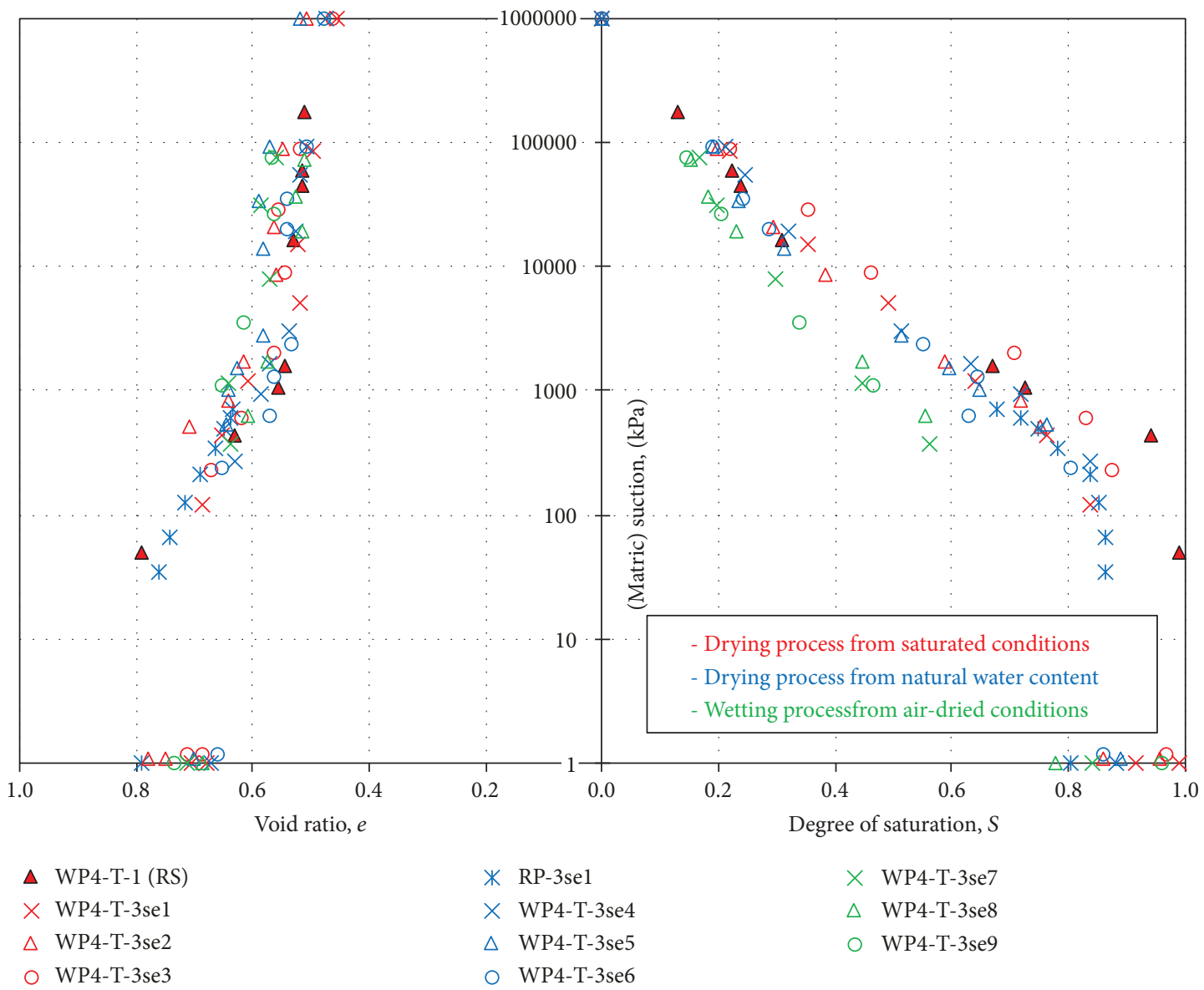

Figure 7: S- $\psi$-e measurements obtained using the WP4-T and pressure plate extractor apparatus.
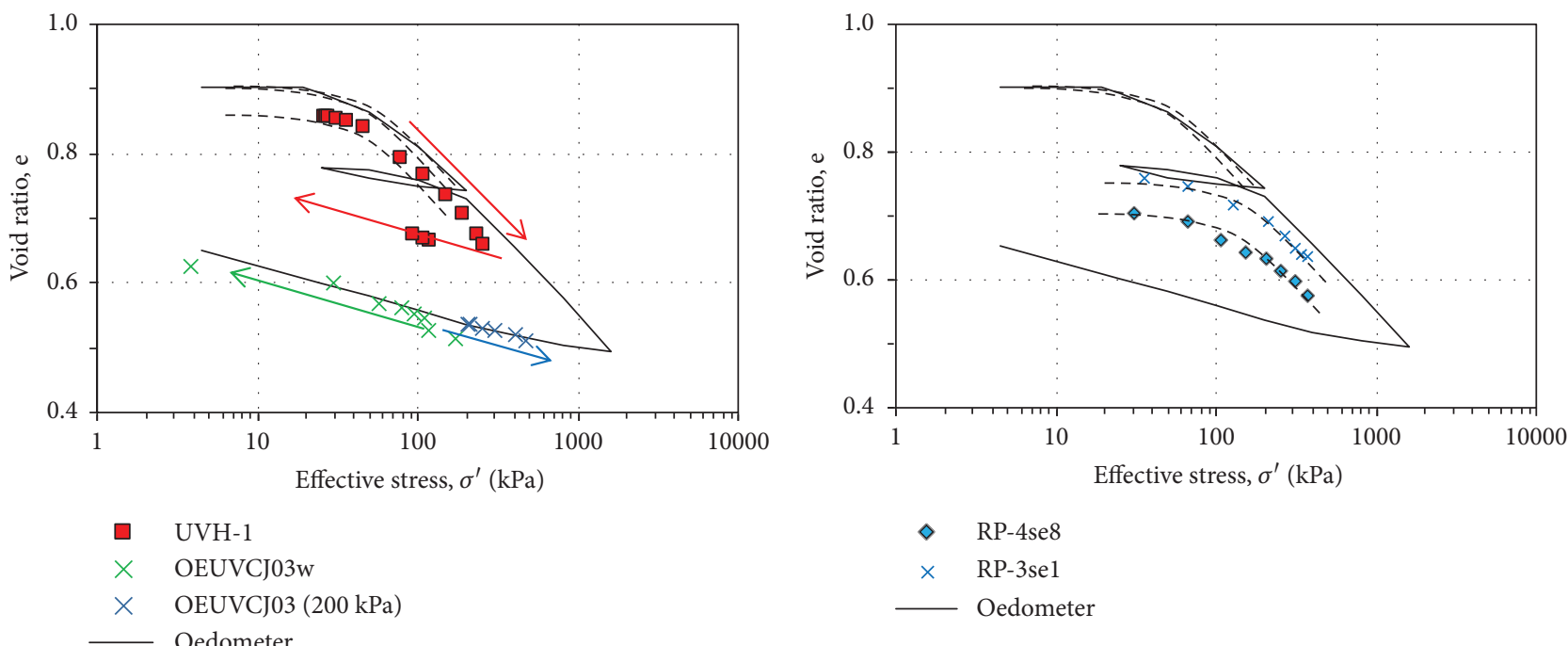

(a)

(b)

FIGURE 8: Results in terms of $\sigma^{\prime}-e$ compared with the conventional oedometer test results for the (a) UVH-1, OEUVCJ03w, and OEUVCJ03 and (b) RP-3se1 and RP4-se8 tests.

in these tests, during both the drying and the wetting processes. The undisturbed specimen in the UVH-1 test was saturated using the incremental back-pressurization procedure and consolidated at $25 \mathrm{kPa}$ of net vertical stress. Next, the material was dried, increasing the matric suction up to $250 \mathrm{kPa}$, and then wetted to $80 \mathrm{kPa}$ of matric suction. The 
specimen in the UVH-1 test behaves as an over-consolidated material until the increase in suction causes the effective stress to increase beyond the preconsolidation pressure of $50 \mathrm{kPa}$ (determined in the standard oedometer test). From this point, the results follow the slope of the virgin compression line $\left(C_{\mathrm{c}}=0.262\right)$. Due to a decrease in the matric suction, the results along the wetting path follow the slope of the swelling curve $\left(C_{\mathrm{s}}=0.065\right)$, suggesting a suctionover-consolidated material. A similar behavior is observed for the suction-over-consolidated specimen OEUVCJ03. The oven-dried sample for this test was equilibrated at $490 \mathrm{kPa}$ of matric suction and incrementally wetted to $0 \mathrm{kPa}$ of suction. During the wetting process, the specimen follows the swelling line obtained from the standard oedometer test. After absorbing water and reaching equilibration at atmospheric pressure, the specimen was consolidated at an effective stress of $200 \mathrm{kPa}$. Finally, the matric suction was increased to $350 \mathrm{kPa}$ under a constant net vertical stress. Again, the specimen behaves as a preconsolidated material, following the slope of the swelling curve in the $\log \left(\sigma^{\prime}\right)$-e plane. The results obtained using the standard pressure plate extractor on the samples that start the drying process from the natural water content, the RP-3se1 and $\mathrm{RP}-4$ se 8 tests, are shown together with the results obtained using the conventional oedometer apparatus in Figure 8(b). Using the same formulation to determine $\sigma^{\prime}$, the preconsolidation pressure due to the suction seems to be slightly higher for this specimen.

Using the same formulation for the effective stress, the results obtained using the WP4-T device in the WP4-T-1 and WP4-T-3se1, WP4-T-3se2, WP4-T-3se3, WP4-T-3se4, WP4-T-3se5, and WP4-T-3se6 tests are shown in Figure 9. Depending on the achieved suction during the drying process, the undisturbed specimens from the WP4-T-3 test follow the same behavior pattern as seen in the results from the suction-controlled oedometer devices. A completely different behavior pattern is observed in the case of the remolded specimens in the WP4-T-1 test, in which the specimens behave as a normally consolidated material, undergoing a large reduction in the void ratio from the beginning of the drying process.

The Khalili and Khabbaz's effective stress parameter [51] seems to reasonably predict the effective stress for suctions up to $8000 \mathrm{kPa}$. However, using a fixed value for the fitting parameter $(-0.55)$ seems to overestimate the increase in effective stress due to the increase in suction for suctions higher than $8000 \mathrm{kPa}$, according to the standard oedometer results.

\section{Interpretation and Discussion}

For modeling, comparison, and characterization purposes, it is useful to present the fragmented SWCC laboratory measurements in the form of a mathematical equation. Consequently, a continuous function is obtained for a wide range of suctions. A nonlinear regression analysis was performed using the "solver" add-in in Microsoft Excel on the results obtained during the drying and wetting process. The bestfit equation parameters were obtained by minimizing the

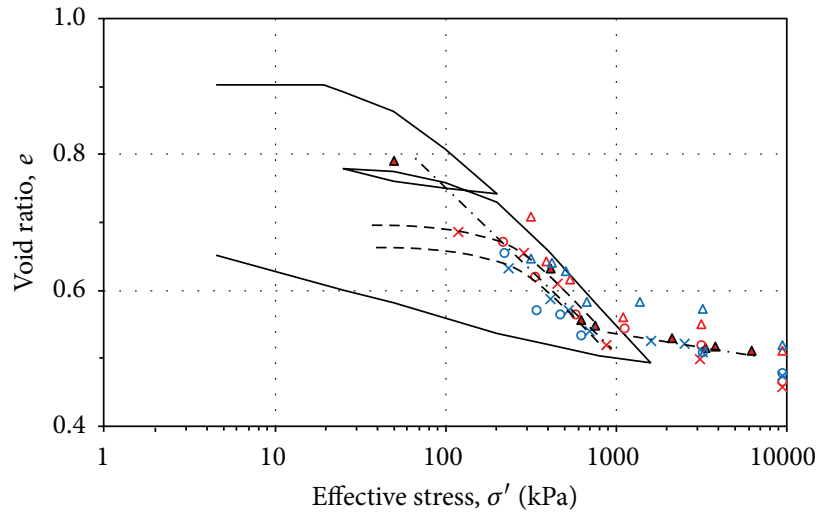
$\Delta$ WP4-T-1
$\triangle$ WP4-T-3se2
WP4-T-3se4
WP4-T-3se6

$\begin{array}{cl}\times & \text { WP4-T-3se1 } \\ \bigcirc & \text { WP4-T-3se3 } \\ \triangle & \text { WP4-T-3se5 } \\ & \text { Oedometer }\end{array}$

FIGURE 9: Results in terms of $\sigma^{\prime}-e$ compared with the conventional oedometer test results for the WP4-T-1 and WP4-T-3se1, WP4-T3se2, WP4-T-3se3, WP4-T-3se4, WP4-T-3se5, and WP4-T-3se6 tests.

objective function with respect to the sum of the squared residuals (SSR). Smaller values of the SSR imply a better fit between the measured and the calculated values using the different SWCC equations. Three of the most frequently used equations were used to fit the obtained measurements: Brooks and Corey (BC) [41], van Genuchten (VG) [57], and Fredlund and Xing [58].

Brooks and Corey's SWCC equation [41] is given by

$$
\begin{aligned}
& \theta=\theta_{\mathrm{s}}, \\
& \theta=\theta_{\mathrm{s}}\left(\frac{\psi_{b}}{\psi}\right)^{\lambda}, \quad \psi \leq \psi_{b}, \psi>\psi_{b},
\end{aligned}
$$

where $\theta$ is the volumetric water content, $\theta_{\mathrm{s}}$ is the saturated volumetric water content, $\psi$ is the matric suction, $\psi_{b}$ is the AEV of the soil, and $\lambda$ is a constant.

Van Genuchten's SWCC equation [57] is given by

$$
\theta=\theta_{s}\left[\frac{1}{1+(\alpha \psi)^{n}}\right]^{m},
$$

where $\alpha, n$, and $m$ are constants.

Fredlund and Xing's SWCC equation [58] is given by

$$
\theta=C(\psi) \frac{\theta_{s}}{\left\{\ln \left[e+(\psi / a)^{n}\right]\right\}^{m}},
$$

where $a, n$, and $m$ are constants and $C(\psi)$ is a correction function defined as $C(\psi)=\left(-\ln \left(1+\left(\psi / \psi_{r}\right)\right) / \ln [1+(1,000\right.$, $\left.\left.\left.000 / \psi_{r}\right)\right]\right)+1$.

Although a sharp discontinuity near saturation in the BC equation very often limits its practical application for modeling purposes, it is one of the oldest equations and is valuable for comparing the soil-water characteristics of different soils using the existing databases. As it is expected from the 
obtained SWCC shape, the sigmoidal equations (VG and FX) performed better than the nonsigmodal (BC) equation, while the FX equation performed slightly better than the VG equation. A higher number of fitting parameters provided a stronger correlation, in all the considered cases.

5.1. Interpretation for the Drying Branch of the SWCC. The UVH-1 test results were used for the fitting in the initial part of the desorption branch of the SWCC and the determination of the saturated water content $\theta_{\mathrm{s}}$. Starting from the saturated conditions and using the results from only those tests with a net vertical stress of $25 \mathrm{kPa}$, the UVH-1 test results represent the upper bounding curve. The WP4-T-3 test measurements on initially saturated specimens were used to extend the SWCC in the region of higher suction values. The results obtained from the WP4-T-3se3 test plot higher than the rest of the results obtained starting from the saturated conditions. Although this is probably due to the specimen inhomogeneity, the exclusion of the WP4-T-3se3 resulted in a significant decrease in the SSR value, from 0.00270 to 0.00039 in the case of the FX equation and from 0.00283 to 0.00054 in the case of the VG equation. In the case of the BC equation, only a slight decrease in the SSR value, from 0.00702 to 0.00428 , was obtained by omitting the WP4-T-3se3 results.

Using the three-parameter form of the FX equation ("correction" factor $C(\psi)=1$ [58]) causes an increase in the SSR value, from 0.00039 to 0.00058 . Leaving the $m$ and $n$ parameters with no fixed relationship provides a slightly lower value of the SSR (0.00049) than that obtained when fixing these parameters using the relation $m=1-1 / n$ (0.00054), as used in van Genuchten [57] when trying to obtain a closed-form expression for hydraulic conductivity.

Considering that suctions as low as 2.1 and $1 \mathrm{kPa}$ were used in the fitting procedure for the drying branch, the saturated volumetric water content did not affect the result significantly if kept as a constant value $\left(\theta_{s}=0.4625\right)$ or used as another fitting parameter for the VG and FX equations. However, due to the limitation of the $\mathrm{BC}$ equation to predict the water contents of soils that exhibit volume changes below the AEV, the best fit was obtained for a slightly lower value, $\theta_{\mathrm{s}}=0.450$.

The curves and best-fit parameters obtained by using the nonlinear regression procedure on measurements performed on undisturbed specimens in the (main) drying and wetting processes are presented in Tables 2 and 3 and Figure 10.

5.2. Interpretation for the Wetting Branch of the SWCC. The results obtained from the VE-1w and WP4-T-3se7, WP4-T3 se 8 , and WP4-T-3se9 tests were used to fit the parameters of all three equations in the case of the adsorption branch of the SWCC. Only the last measurement from the WP4-T3 se 7 test, at a total suction of $370 \mathrm{kPa}$, was excluded from the nonlinear regression procedure, since it plots slightly lower in the $\psi-\theta$ plane, causing a slight increase in the SSR value from 0.00025 to 0.00047 for the FX equation. The results obtained from air-dried samples represent the lower bounding curve of the SWCC.

The highest volumetric water content of 0.335 did not change significantly if it was used as a fitting parameter for the FX and VG equations. Again, for the BC equation, the best fit was obtained for a slightly lower value (0.307).

5.3. Prediction Models. Two correlation models that predict the SWCC for plastic materials were tested on the obtained results along the drying and wetting paths. The FX equation parameters were obtained by using the correlation models proposed by Zapata [59] and Perera et al. [46]. Both models use only two basic material properties: the percent passing through number 200 sieve $\left(\mathrm{P}_{200}\right)$ and PI. The SSR values indicate the level of convergence between the measured and the model-predicted values. The obtained curves are shown in Figure 11, together with the previously derived best-fit FX curve. Table 4 presents the calculated parameters. During both the drying and the wetting process, the Zapata [59] model seems to perform reasonably well. On the other hand, the model proposed by Perera et al. [46] was unable to accurately predict the SWCC, especially for the drying process $(\mathrm{SSR}=0.103)$. However, it was noted that this model performed much better if the clay percentage (30.3\%) was used instead of $\mathrm{P}_{200}$ (Figure 11).

The hydromechanical features of the tested soil are compared with Guadalix Red silty clay [60], which is $48 \%$ silt and has $w_{\mathrm{L}}=33 \%$ and $\mathrm{PI}=13.6 \%$. According to the SWCC parameters $\psi_{\mathrm{r}}=19.6 \mathrm{MPa}, a=242.1, n=0.81$, and $m=0.79$ [61], two materials closely match. If the obtained retention model parameters are compared with the average values for different soil textural groups [62], it is clear that the complex origin process generates interesting hydromechanical features in this soil. The saturated and residual volumetric water contents correspond to the silts, while $\alpha=0.005$ and $n=$ 1.332 are characteristic values for the silty clay and clay loam textures, respectively. On the other hand, the saturated shear strength parameters determined in the previous studies [2] are commonly obtained in materials with a significant portion of sandy particles.

\section{Conclusions}

The soil-water characteristic curves (SWCCs) of residual soil formed by the weathering process of a flysch rock mass have been presented in this paper. A wide range of pore sizes present in the material results in gentle slopes of the SWCC, covering a wide range of suctions. The measurements performed on air-dried specimens indicated suction values higher than $90 \mathrm{MPa}$ for undisturbed specimens and $175 \mathrm{MPa}$ for remolded specimens. Six different devices were used to perform measurements on the undisturbed specimens in all three characteristic zones of the SWCC. The water retention characteristics were determined using intact specimens undergoing the drying and wetting processes, from different initial water contents. Due to the volumetric changes that the material undergoes during the change in suction, all the tests were performed in a way that allowed both the total volume and the water volume to be measured. The effects of the overburden pressure on the soil-water characteristics were analyzed using the suction-controlled oedometers during the drying and wetting processes. The density measurements collected by using the wax dipping and water displacement 
TABLE 2: Best-fit parameters and SSR values for the two- and three-parameter equations: the Brooks and Corey [41], van Genuchten [57], and Fredlund and Xing [58] equations.

\begin{tabular}{lcccccccccc}
\hline & \multicolumn{4}{c}{ Brooks and Corey eq. [41] } & \multicolumn{4}{c}{ Three-parameter equations } \\
$\theta_{\text {sd }}=0.4625 ; \theta_{\text {sw }}=0.335$ & SSR $\left(r^{2}\right)$ & $\theta_{\mathrm{r}}$ & $\psi_{\mathrm{b}}$ & $\lambda$ & SSR $\left(r^{2}\right)$ & $\theta_{\mathrm{r}}$ & $\alpha$ & $m^{*}$ \\
\hline Bounding drying curve & 0.00428 & 0 & 99.491 & 0.260 & 0.00054 & 0.013 & 0.005 & 1.332 & 0.249 \\
Bounding wetting curve & 0.00203 & 0 & 72.567 & 0.246 & 0.00033 & 0.000 & 0.008 & 1.280 & 0.219 \\
\hline
\end{tabular}

TABLE 3: Best-fit parameters and SSR values for the four-parameter equations: the van Genuchten [57] and Fredlund and Xing [58] equations.

\begin{tabular}{lccccccccccc}
\hline & \multicolumn{1}{c}{ Fan Genuchten [57]; $m$ free } & \multicolumn{3}{c}{ Four-parameter equations } & \multicolumn{4}{c}{ Fredlund and Xing [58] } \\
$\theta_{\text {sd }}=0.4625 ; \theta_{\text {sw }}=0.335$ & SSR $\left(r^{2}\right)$ & $\theta_{\mathrm{r}}$ & $\alpha$ & $n$ & $m$ & SSR $\left(r^{2}\right)$ & $\psi_{\mathrm{r}}$ & $a$ & $n$ \\
\hline Bounding drying curve & 0.00049 & 0.028 & 0.004 & 1.186 & 0.323 & 0.00039 & 177720.9 & 299.753 & 1.073 & 0.907 \\
Bounding wetting curve & 0.00021 & 0.011 & 0.005 & 0.973 & 0.348 & 0.00022 & 254164.3 & 284.117 & 0.859 & 1.053 \\
\hline
\end{tabular}

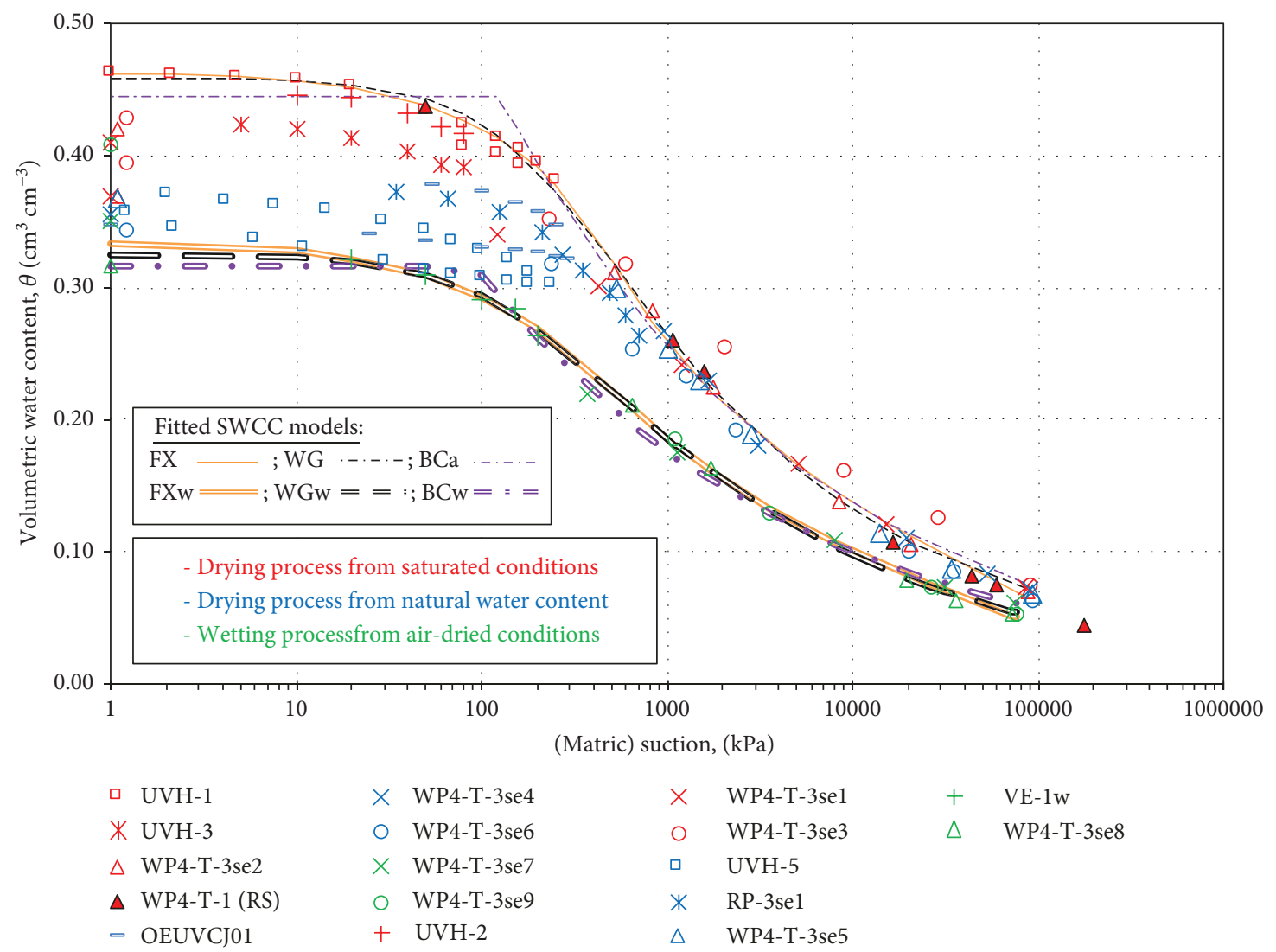

Figure 10: Best-fit Brooks and Corey [41], van Genuchten [57], and Fredlund and Xing [58] equations plotted with the measurements in $\psi-\theta$ plane.

technique and standard null-type pressure plate devices provided the SWCC- $\theta$ measurements for the undisturbed specimens undergoing drying, for up to $700 \mathrm{kPa}$ of matric suction. The density measurements combined with the WP4-T device provided the water retention characteristics of the undisturbed specimens undergoing the drying or wetting process for suction values lower than $1 \mathrm{MPa}$ and higher than $175 \mathrm{MPa}$. The obtained results showed a good agreement with the measurements performed by using the axis translation technique for suction values as low as $300 \mathrm{kPa}$, suggesting that the use of undisturbed specimens should be preferred in this case. The measurements performed with the WP4-T device from the remolded specimens converge with the measurements obtained from the undisturbed specimens at suction values higher than $1 \mathrm{MPa}$ during the drying process and $6 \mathrm{MPa}$ during the wetting process. A nonlinear regression 


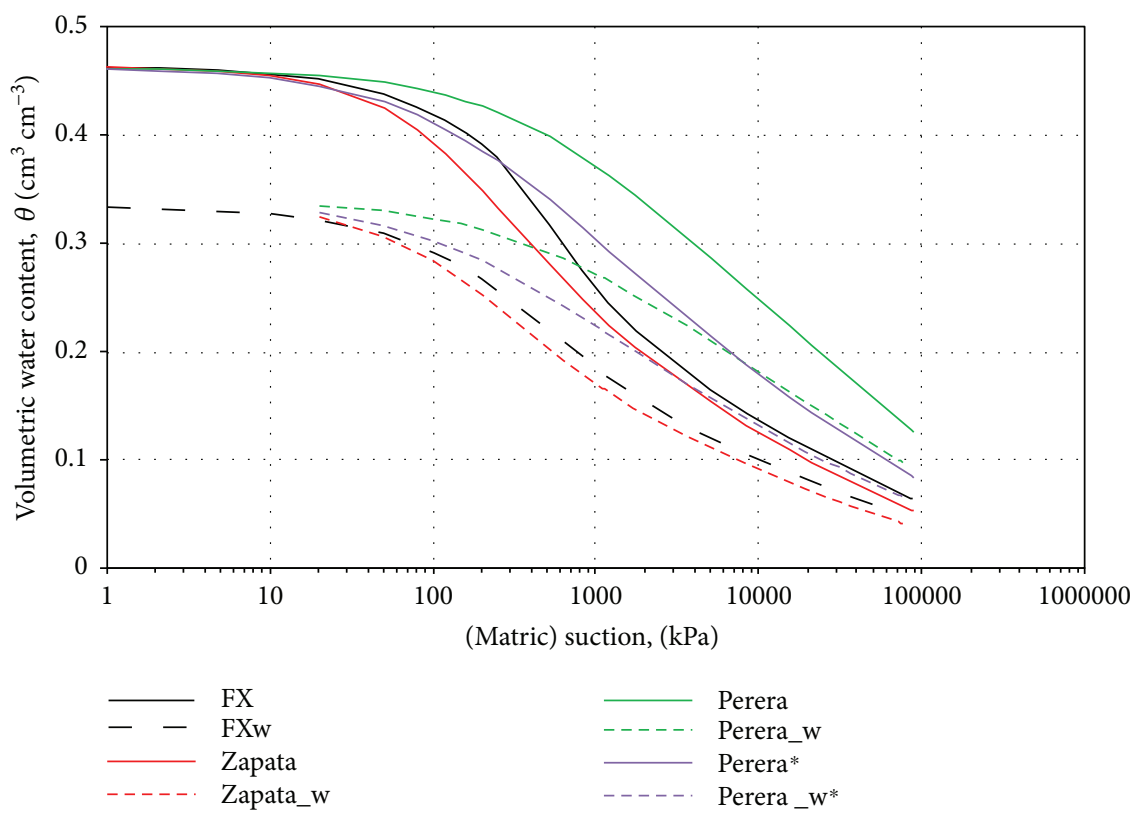

Figure 11: Performance of the two prediction models compared with the Fredlund and Xing [58] equation obtained by using the nonlinear regression procedure on the measured data.

TABLE 4: Fredlund and Xing [58] equation parameters and SSR values obtained using the Zapata [59] and Perera et al. [46] correlation models for the SWCC.

\begin{tabular}{|c|c|c|c|c|c|c|}
\hline \multirow[b]{2}{*}{$\theta_{\text {sd }}=0.4625 ; \theta_{\text {sw }}=0.335$} & \multicolumn{6}{|c|}{ Fredlund and Xing [58] equation } \\
\hline & $\mathrm{SSR}_{\mathrm{d}}$ & $\mathrm{SSR}_{\mathrm{w}}$ & $\psi_{\mathrm{rf}}$ & $a_{\mathrm{f}}$ & $n_{\mathrm{f}}$ & $m_{\mathrm{f}}$ \\
\hline Zapata correlation [59] & 0.01109 & 0.00227 & 5385.4 & 121.911 & 1.085 & 0.690 \\
\hline Perera et al. correlation [46] & 0.10287 & 0.07522 & 500.0 & 123.599 & 0.587 & 0.116 \\
\hline Perera correlation $[46]^{*}$ & 0.01526 & 0.01237 & 500.0 & 91.597 & 0.801 & 0.326 \\
\hline
\end{tabular}

${ }^{*}$ Clay percentage, C (\%) instead of $\mathrm{P}_{200}$

analysis was performed on the results obtained during the drying and wetting processes to obtain the best-fit equation and parameters of three of the most commonly used SWCC equations: Brooks and Corey [41], van Genuchten [57], and Fredlund and Xing [58]. Obtained results are valuable for further research of rainfall-induced landslides in flysch slopes. Rainfall infiltration through initially unsaturated residual soil can be simulated as a transient process in order to investigate the influence of different initial conditions (moisture contents) of the geotechnical cross-section and rainfall characteristics on the pore water pressure changes and, consequently, changes in slope stability state in time.

\section{Data Availability}

All the data obtained in this study are included in the article. Graphically presented data are available in text form from the corresponding author upon request.

\section{Conflicts of Interest}

The authors declare that there are no conflicts of interest regarding the publication of this paper.

\section{Acknowledgments}

The experimental tests were performed in three different Laboratories of Geotechnics: (i) University of Rijeka (Croatia), (ii) University of Salerno (Italy), and (iii) University of Ljubljana (Slovenia), in the frame of the following projects: Bilateral Slovenian-Croatian research Project "Laboratory investigations and numerical modelling of landslides in flysch deposits in Croatia and Slovenia" and "Erasmus+ Programme of the European Union". The part of laboratory equipment used for laboratory testing was provided in the frame of Project "Research Infrastructure for Campusbased Laboratories at the University of Rijeka", co-funded in part by the Ministry of Science, Education and Sports of the Republic of Croatia and the European Fund for Regional Development (ERDF). The authors are also grateful to Engr. Vito Foresta and Dr. Mariagiovanna Moscariello who contributed to the experimental activities in Salerno.

\section{References}

[1] Ž. Arbanas, S. Dugonjić Jovančević, M. Vivoda, and S. Mihalić Arbanas, "Study of landslides in flysch deposits of North Istria, 
Croatia: landslide data collection and recent landslide occurrences," in Proceedings of the WLF 3, Landslide Science for a Safer Geoenvironment, Volume 1: The International Programme on Landslides (IPL), K. Sassa, P. Canuti, and Y. Yin, Eds., pp. 89-94, Springer, Switzerland, 2014.

[2] M. Vivoda Prodan, M. Mileusnić, S. Mihalić Arbanas, and $\check{Z}$. Arbanas, "Influence of weathering processes on the shear strength of siltstones from a flysch rock mass along the northern Adriatic coast of Croatia," Bulletin of Engineering Geology and the Environment, vol. 76, no. 2, pp. 695-711, 2017.

[3] M. Vivoda Prodan and Ž. Arbanas, "Weathering influence on properties of siltstones from Istria, Croatia," Advances in Materials Science and Engineering, vol. 2016, Article ID 3073202, 15 pages, 2016.

[4] S. Vanapalli, "Simple test procedures and their interpretation in evaluating the shear strength of an unsaturated soil," $\mathrm{PhD}$ thesis, University of Sasatchewan, Canada, 1994.

[5] P. Marinos and E. Hoek, "Estimating the geotechnical properties of heterogeneous rock masses such as flysch," Bulletin of Engineering Geology and the Environment, vol. 60, no. 2, pp. 85-92, 2001.

[6] S. Dugonjić Jovančević and Ž. Arbanas, "Recent landslides on the Istrian Peninsula, Croatia," Natural Hazards, vol. 62, no. 3, pp. 1323-1338, 2012.

[7] D. M. Cruden and D. J. Varnes, "Landslide types and processes," Landslides: Investigation and Mitigation (Special Report), A. K. Turner and R. L. Schuster, Eds., National Research Council, Transportation and Research Board Special Report 247, Washington, DC, USA, 1996.

[8] O. Hungr, S. Leroueil, and L. Picarelli, "The Varnes classification of landslide types, an update," Landslides, vol. 11, no. 2, pp. 167-194, 2014.

[9] S. Mihalić Arbanas, M. Sečanj, S. Bernat Gazibara, M. Krkač, and $\check{Z}$. Arbanas, "Identification and mapping of the Valići Lake Landslide (Primorsko-Goranska County, Croatia)," Proceedings of the 2nd Regional Symposium on Landslides, 2017, pp. 197-202, Belgrade, May 2015.

[10] G. Tosatti, D. Castaldini, M. Barbieri et al., "Additional causes of seismical related landslides in the Northern Apennines, Italy," Revista de Geomorfologie, vol. 10, pp. 5-21, 2008.

[11] E. Gil and M. Dlugosz, "Threshold values of rainfalls triggering selected deep-seated landslides in the polish flysch Carpathians," Studia Geomorphologica Carpatho-Balcanica, vol. 40, pp. 21-43, 2006.

[12] M. Polemio, "Rainfall and Senerchia Landslides, Southern Italy," in ABMS-ISSMFE, 2nd Panamerican Symposium on Landslides, pp. 175-184, Rio De Janeiro, Brasil, January 1997.

[13] J. Logar, K. Fifer Bizjak, M. Kočevar, M. Mikoš, M. Ribičič, and B. Majes, "History and present state of the Slano Blato Landslide," Natural Hazards and Earth System Sciences, vol. 5, no. 3, pp. 447-457, 2005.

[14] J. Klimeš, I. Baron, T. Panek et al., "Investigation of recent catastrophic landslides in the flysch belt of Outer Western Carpathians (Czech Republic): progress towards better hazard assessment," Natural Hazards and Earth System Sciences, vol. 9, no. 1, pp. 119-128, 2009.

[15] Ž. Arbanas, S. Mihalić Arbanas, M. Vivoda Prodan et al., "Preliminary investigations and numerical simulations of a landslide reactivation," in Advancing Culture of Living with Landslides. WLF 2017, M. Mikos, B. Tiwari, Y. Yin, and K. Sassa, Eds., pp. 649-657, Springer, Cham, 2017.
[16] ASTM D854-14, Standard Test Methods for Specific Gravity of Soil Solids by Water Pycnometer, ASTM International, West Conshohocken, PA, USA, 2014.

[17] ASTM D1140-17, Standard Test Methods for Determining the Amount of Material Finer than 75- $\mu m$ (No. 200) Sieve in Soils by Washing, ASTM International, West Conshohocken, PA, USA, 2017.

[18] ASTM D7928-17, Standard Test Method for Particle-Size Distribution (Gradation) of Fine-Grained Soils Using the Sedimentation Analysis, ASTM International, West Conshohocken, PA, USA, 2017.

[19] ASTM D4318-17, Standard Test Methods for Liquid Limit, Plastic Limit, and Plasticity Index of Soils, ASTM International, West Conshohocken, PA, USA, 2017.

[20] ASTM D2487-11, Standard Practice for Classification of Soils for Engineering Purposes (Unified Soil Classification System), ASTM International, West Conshohocken, PA, USA, 2011.

[21] S. Salager, M. S. el Youssoufi, and C. Saix, "Definition and experimental determination of a soil-water retention surface," Canadian Geotechnical Journal, vol. 47, no. 6, pp. 609-622, 2010.

[22] D. Fredlund and S. L. Houston, Interpretation of Soil-Water Characteristic Curves When Volume Change Occurs as Soil Suction Is Changed, Taylor \& Francis Group, Cartagena de Indias, Colombia, 2013.

[23] C. W. W. Ng and Y. W. Pang, "Influence of stress state on soilwater characteristics and slope stability," Journal of Geotechnical and Geoenvironmental Engineering, vol. 126, no. 2, pp. 157-166, 2000.

[24] A. Tarantino, "A water retention model for deformable soils," Geotechnique, vol. 59, no. 9, pp. 751-762, 2009.

[25] S. K. Vanapalli, D. G. Fredlund, and D. E. Pufahl, “The influence of soil structure and stress history on the soil-water characteristics of a compacted till," Geotechnique, vol. 49, no. 2, pp. 143-159, 1999.

[26] X. Zhang, M. Mavroulidou, and M. J. Gunn, "A study of the water retention curve of lime-treated London Clay," Acta Geotechnica, vol. 12, no. 1, pp. 23-45, 2017.

[27] G. W. Gee, M. D. Campbell, G. S. Campbell, and J. H. Campbell, "Rapid measurement of low soil water potentials using a water activity meter," Soil Science Society of America Journal, vol. 56, no. 4, pp. 1068-1070, 1992.

[28] R. Cardoso, E. Romero, A. Lima, and A. Ferrari, "A comparative study of soil suction measurement using two different high-range psychrometers," in Experimental Unsaturated Soil Mechanics. Springer Proceedings in Physics, vol 112, T. Schanz, Ed., pp. 79-93, Springer, Berlin, Heidelberg, 2007.

[29] E.-C. Leong, S. Tripathy, and H. Rahardjo, "Total suction measurement of unsaturated soils with a device using the chilledmirror dew-point technique," Geotechnique, vol. 53, no. 2, pp. 173-182, 2003.

[30] V. K. S. Thakur, S. Sreedeep, and D. N. Singh, "Laboratory investigations on extremely high suction measurements for fine-grained soils," Geotechnical and Geological Engineering, vol. 24, no. 3, pp. 565-578, 2006.

[31] M. Tuller and D. Or, "Water films and scaling of soil characteristic curves at low water contents," Water Resources Research, vol. 41, no. 9, pp. 1-6, 2005.

[32] S. S. Agus and T. Schanz, "Comparison of four methods for measuring total suction," Vadose Zone Journal, vol. 4, no. 4, pp. 1087-1095, 2005. 
[33] G. S. Campbell, D. M. Smith, and B. L. Teare, "Application of a dew point method to obtain the soil-water characteristics," in Experimental Unsaturated Soil Mechanics. Springer Proceedings in Physics, vol 112, T. Schanz, Ed., pp. 71-77, Springer, Berlin, Heidelberg, 2007.

[34] K. A. Bocking and D. Fredlund, "Limitations of the axis translation technique," Fourth International Conference on Expansive Soils, 1980, pp. 117-135, Denver, CO, USA, June 1980.

[35] ASTM D7263-09, Standard Test Methods for Laboratory Determination of Density (Unit Weight) of Soil Specimens, ASTM International, West Conshohocken, PA, USA, 2009.

[36] ASTM D6836-02, Standard Test Methods for Determination of the Soil Water Characteristic Curve for Desorption Using a Hanging Column, Pressure Extractor, Chilled Mirror Hygrometer, and/or Centrifuge, ASTM International, West Conshohocken, PA, USA, 2002.

[37] U. Schindler, "Ein schnellverfahren zur messung der wasserleitfähigkeit im teilgesättigten boden an stechzylinderproben. s.l.," Archiv für Acker- und Pflanzenbau und Bodenkunde, vol. 24, pp. 1-7, 1980.

[38] U. Schindler, W. Durner, G. von Unold, L. Mueller, and R. Wieland, "The evaporation method: extending the measurement range of soil hydraulic properties using the air-entry pressure of the ceramic cup," Journal of Plant Nutrition and Soil Science, vol. 173, no. 4, pp. 563-572, 2010.

[39] A. Pasha, A. Khoshghalb, and N. Khalili, Common Mistakes in Determination of Air Entry Value from Gravimetric Water Content Based Soil-Water Characteristic Curve, CRC Press, Guilin, China, 2015.

[40] H. Q. Pham and D. G. Fredlund, A Volume-Mass Constitutive Model for Unsaturated Soils, College of Graduate and Postdoctoral Studies, Saskatoon, 2005.

[41] R. Brooks and A. Corey, Hydraulic Properties of Porous Media, Hydrology Papers, Colorado State University, 1964.

[42] M. Wijaya, E. C. Leong, and H. Rahardjo, "Effect of shrinkage on air-entry value of soils," Soils and Foundations, vol. 55, no. 1, pp. 166-180, 2015.

[43] D. G. Fredlund, H. Rahardjo, and M. D. Fredlund, Unsaturated Soil Mechanics in Engineering Practice, John Wiley \& Sons, Inc., New Jersey, Hoboken, 2012.

[44] D. G. Fredlund, D. Sheng, and J. Zhao, "Estimation of soil suction from the soil-water characteristic curve," Canadian Geotechnical Journal, vol. 48, no. 2, pp. 186-198, 2011.

[45] T.-F. Chiu and C. D. Shackelford, "Unsaturated hydraulic conductivity of compacted sand-kaolin mixtures," Journal of Geotechnical and Geoenvironmental Engineering, vol. 124, no. 2, pp. 160-170, 1998.

[46] Y. Perera, C. Zapata, W. Houston, and S. Houston, "Prediction of the soil-water characteristic curve based on grain-sizedistribution and index properties," in Geotechnical Special Publications 130-142 \& GRI-18; Proceedings of the GeoFrontiers 2005 Congress, pp. 49-60, Austin, TX, USA, October 2005.

[47] M. Clarizia, G. Gulla, and G. Sorbino, "Sui meccanismi di innesco dei soil slip," in Proceeding of Convegno Internazionale "La prevenzione delle catastrofi idrogeologiche: il contributo della ricerca scientifica" ALBA 96, pp. 585-597, Alba, Italia, November 1996.

[48] G. B. Crosta and P. Fratini, "Rainfall thresholds for triggering soil slips and debris flow," in Proceedings of the 2nd EGS
Plinius Conference on Mediterranean Storms: Publication CNR GNDCI, pp. 463-487, Siena, 2001.

[49] F. Guzzetti, S. Peruccacci, M. Rossi, and C. P. Stark, “The rainfall intensity-duration control of shallow landslides and debris flows: an update," Landslides, vol. 5, no. 1, pp. 3-17, 2008.

[50] A. W. Bishop, “The principle of effective stress," Teknisk Ukeblad, vol. 106, no. 39, pp. 859-863, 1959.

[51] N. Khalili and M. H. Khabbaz, "A unique relationship for $\chi$ for the determination of the shear strength of unsaturated soils," Geotechnique, vol. 48, no. 5, pp. 681-687, 1998.

[52] S. Oh, N. Lu, Y. K. Kim, S. J. Lee, and S. R. Lee, "Relationship between the soil-water characteristic curve and the suction stress characteristic curve: experimental evidence from residual soils," Geotechnical and Geological Engineering, vol. 138, no. 1, pp. 47-57, 2012.

[53] P. Chen, C. Wei, J. Liu, and T. Ma, "Strength theory model of unsaturated soils with suction stress concept," Journal of Applied Mathematics, vol. 2013, Article ID 756854, 10 pages, 2013.

[54] E. Nikooee, G. Habibagahi, S. M. Hassanizadeh, and A. Ghahramani, "Effective stress in unsaturated soils: a thermodynamic approach based on the interfacial energy and hydromechanical coupling," Transport in Porous Media, vol. 96, no. 2, pp. 369-396, 2013.

[55] W. J. Likos, "Effective stress in unsaturated soil: accounting for surface tension and interfacial area," Vadose Zone Journal, vol. 13, no. 5, article vzj2013.05.0095, 2014.

[56] R. Greco and R. Gargano, "A novel equation for determining the suction stress of unsaturated soils from the water retention curve based on wetted surface area in pores," Water Resources Research, vol. 51, no. 8, pp. 6143-6155, 2015.

[57] M. T. van Genuchten, “A closed-form equation for predicting the hydraulic conductivity of unsaturated soils," Soil Science Society of America Journal, vol. 44, no. 5, pp. 892-898, 1980.

[58] D. G. Fredlund and A. Xing, "Equations for the soil-water characteristic curve," Canadian Geotechnical Journal, vol. 31, no. 4, pp. 521-532, 1994.

[59] C. E. Zapata, Uncertainty in Soil-Water-Characteristic Curve and Impacts on Unsaturated Shear Strength Predictions, $\mathrm{PhD}$ Dissertation, Arizona State University, Tempe, AZ, USA, 1999.

[60] V. Escario and J. Juca, "Strength and deformation of partly saturated soils," in Proceedings of the 12th International Conference on Soil Mechanics and Foundation Engineering, pp. 43-46, Rio de Janeiro, August 1989.

[61] S. Vanapalli, W. Sillers, and M. Fredlund, "The meaning and relevance of residual state to unsaturated soils," in 51st Canadian Geotechnical Conference, Edmonton, Alberta, October 1988.

[62] R. F. Carsel and R. S. Parrish, "Developing joint probability distributions of soil water retention characteristics," Water Resources Research, vol. 24, no. 5, pp. 755-769, 1988. 

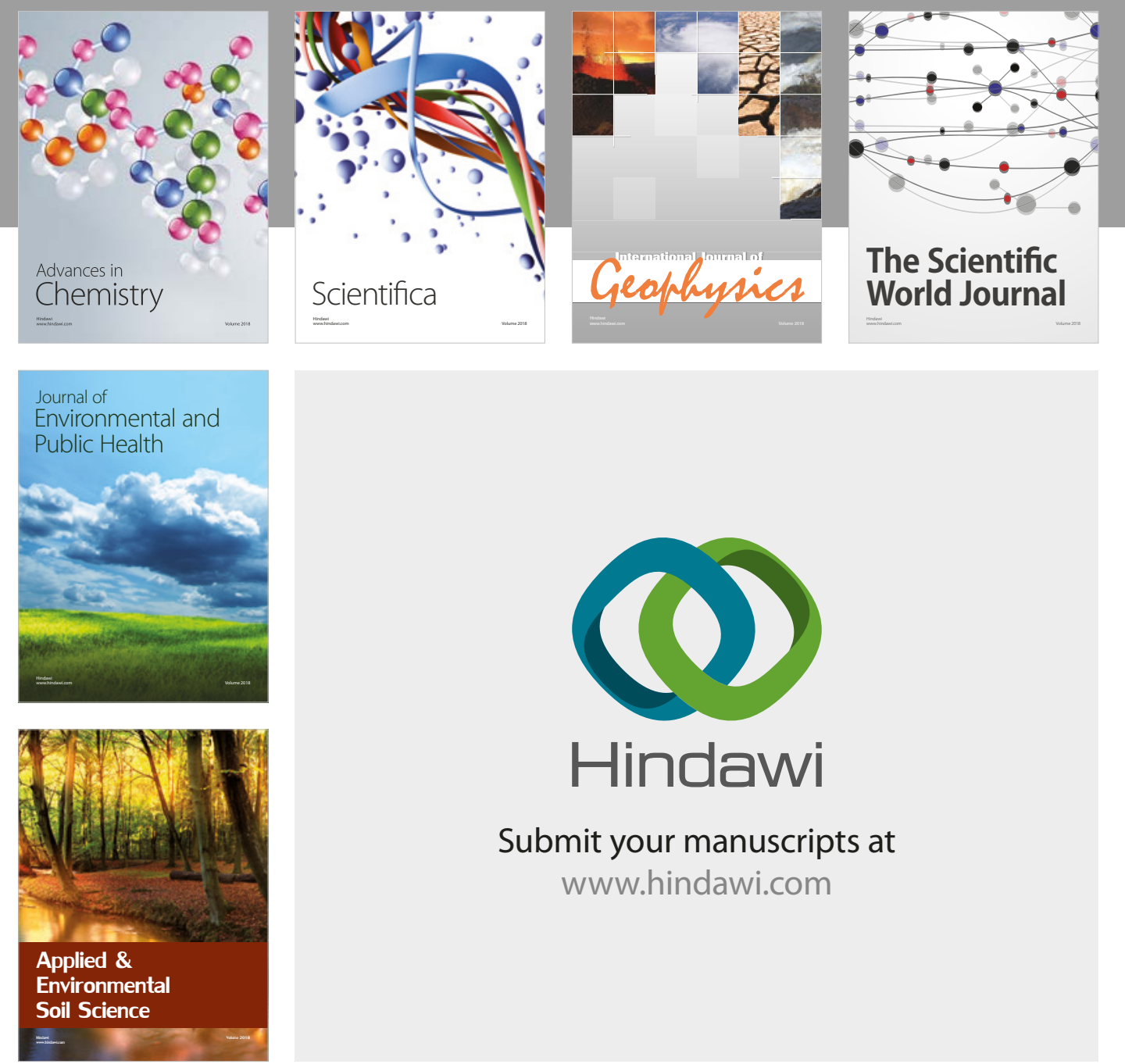

The Scientific

\section{World Journal}
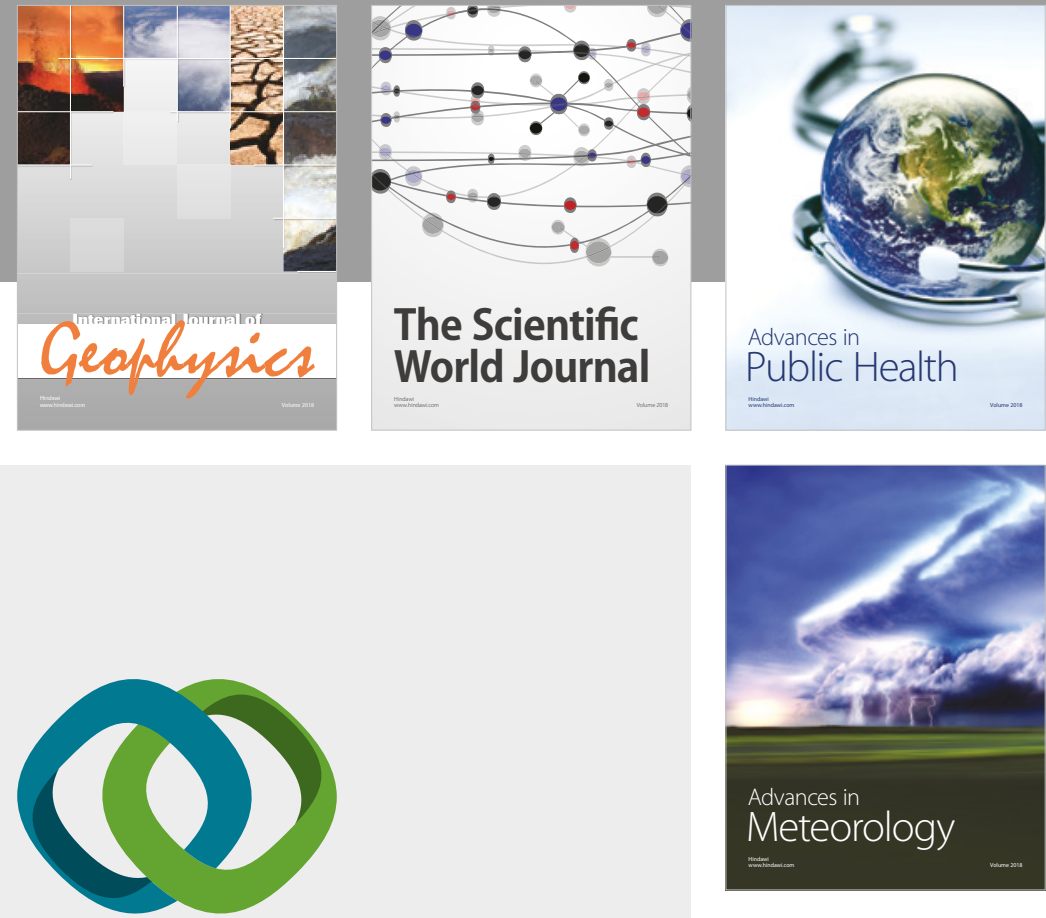

Advan

Public Health

\section{Hindawi}

Submit your manuscripts at

www.hindawi.com
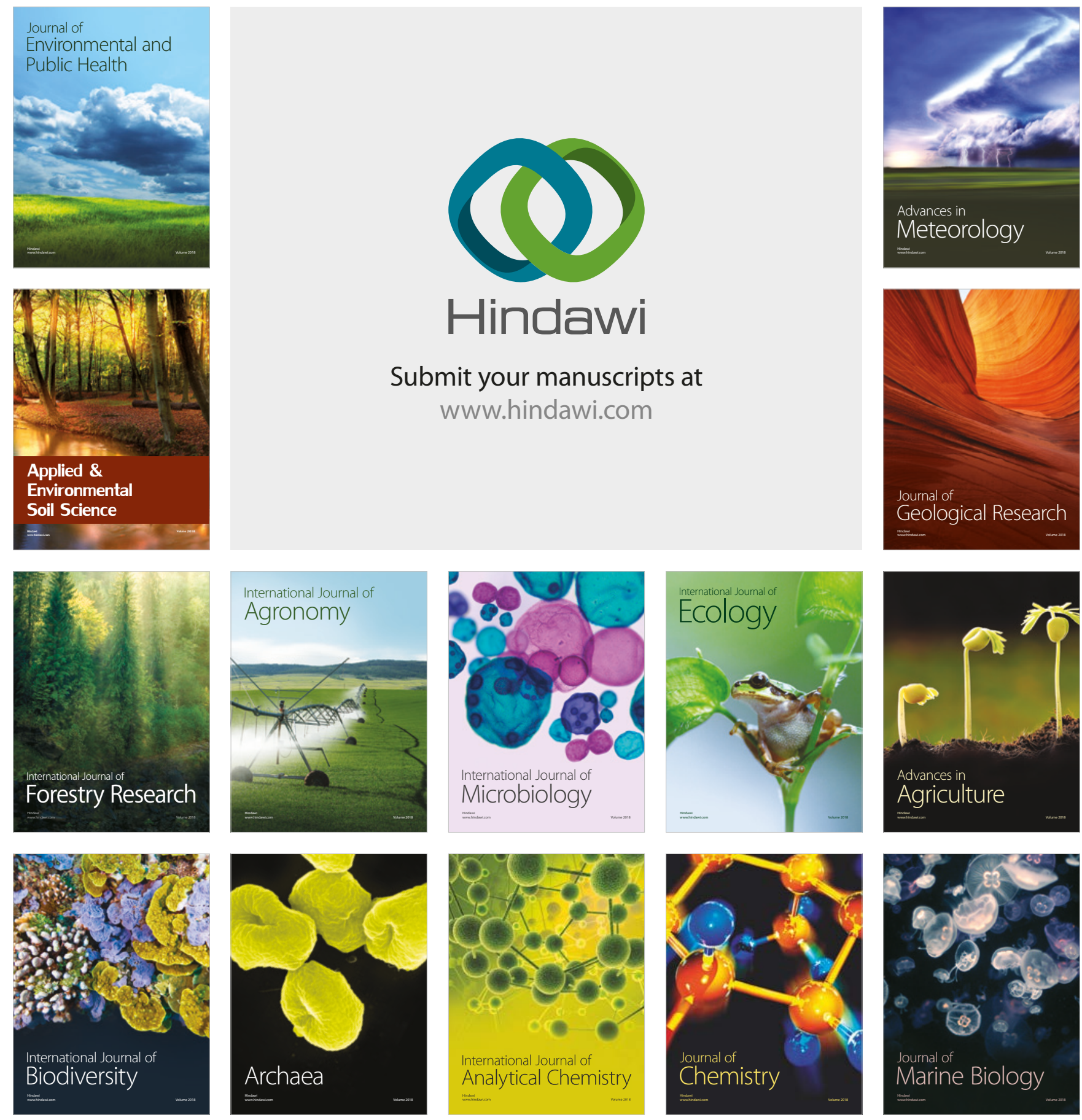